\title{
Spatial patterns in plant diversity
}

\author{
Danilo Coelho de Almeida
}

A thesis submitted as partial fulfilment for the degree of

Master of Science in

Conservation Biology

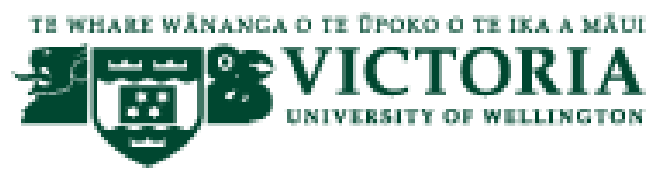

2010 


\section{Thesis abstract}

The present study is divided into two parts: Firstly, null models where used to test whether plant communities in a New Zealand forest were assembled deterministically or stochastically. Secondly, a relationship between a plant trait; Leaf Mass per Area (LMA) and environmental conditions was investigated in a New Zealand forest. For the first study abundance of adult species was recorded in thirty $30 \mathrm{~m} \times 30 \mathrm{~m}$ plots at Otari Wilton's Bush. In a subsample of six plots, the abundance of seedling species was also recorded. Null models for species co-occurrence, species richness, species abundance and niche overlap were used in order to establish how plant communities assemble at Otari Wilton's Bush. There was evidence of both determinist and stochasticity in some aspects of the plant community, it appears that seedlings are mainly randomly assembled whereas, determinism appears to be the main driver of community composition for mature trees. Results therefore suggest a pluralistic approach should be used in order to explain plant community patterns at Otari Wilton's Bush. For the second study, of all species observed in the first study only those species found in five or more of the plots were examined. For those species, the height of the two highest individuals was measured. From each individual, six fully exposed leaves were collected and measured. Measurements of environmental conditions were also collected for all plots. Principal component analysis and multiple regression was used to analyse the data. Height related (vertical) trends were observed for three surveyed species such that LMA significantly increased with plant height. Horizontal patterns were observed for two species, and for three species it was not possible to distinguish the association of tree height (vertical) and position along the forest (horizontal) with LMA. Potentially, by including more species in future studies a clearer pattern will be observed. It could also be that different species display 
different strategies regarding LMA and if so, a study more focused on individual species in isolation may be able to provide more informative explanations. 


\section{Acknowledgements}

I would like to acknowledge:

- my supervisor Dr. K.C. Burns for constructive feedback

- the Wellington Botanical Society for a grant used towards equipment

- the staff at Otari Wilton's Bush

- my partner Megan Humphrey for reading my thesis and providing feedback 


\section{Table of contents}

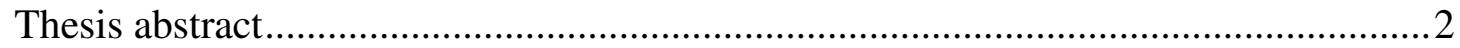

Table of figures and tables............................................................................... 6

Brief introduction study 1: Plant community assembly in a New Zealand forest:

Driven by determinism or randomness? ................................................................

Brief introduction study 2: Relationship between a plant trait and environmental conditions in a New Zealand forest ......................................................................

Chapter 1: Plant community assembly in a New Zealand forest: Driven by

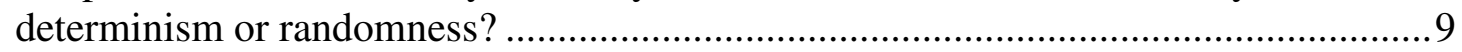

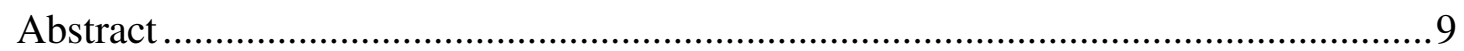

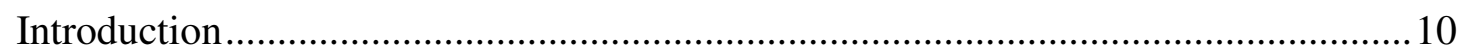

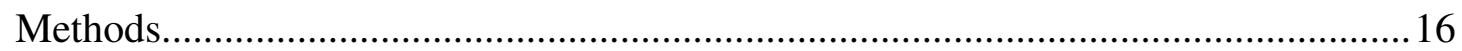

Study site, field sampling and species .................................................................16

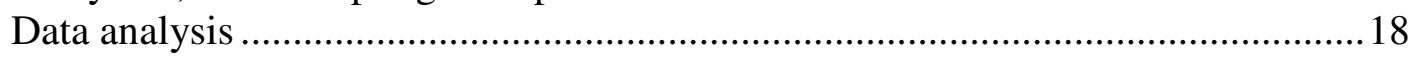

Negative Co-occurrence patterns ....................................................................... 18

Checkerboard species pair analysis ................................................................. 18

Species richness and abundance ………………………............................2

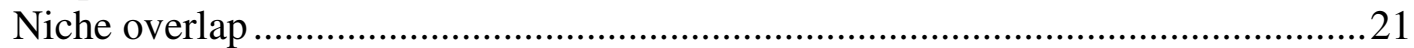

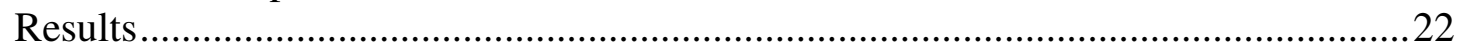

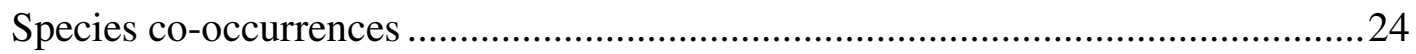

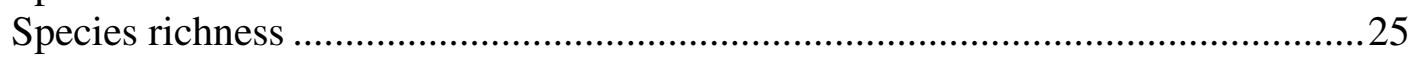

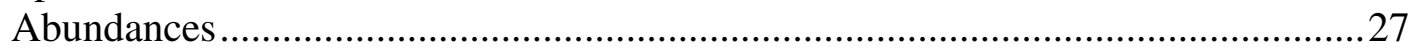

Niche overlap .................................................................................................

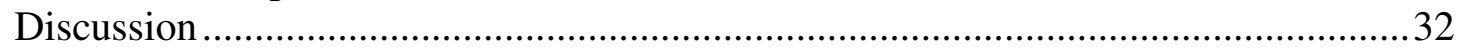

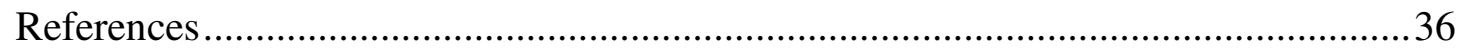

Chapter 2: Relationship between a plant trait and environmental conditions in a New

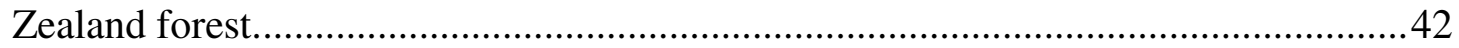

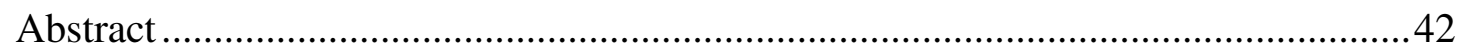



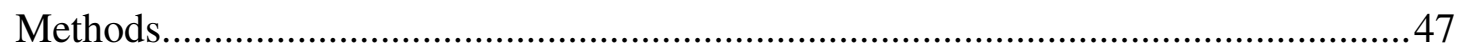

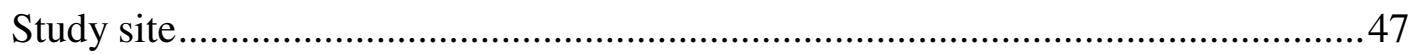

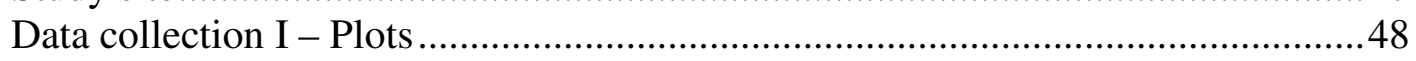

Data collection II - Individual species...................................................................4

Data collection III - physical aspects of plots ......................................................49

Data collection IV - Lab ..............................................................................50



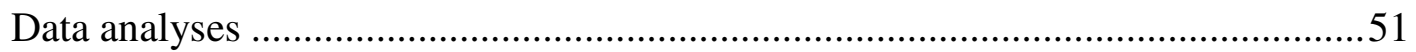

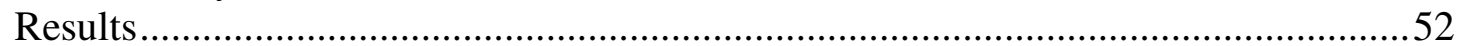

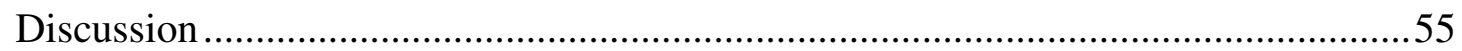

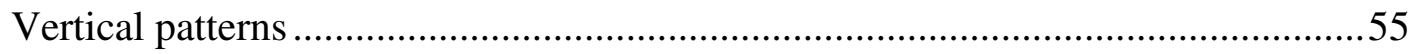

Horizontal patterns .........................................................................................

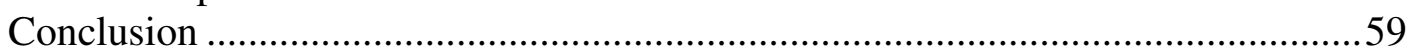

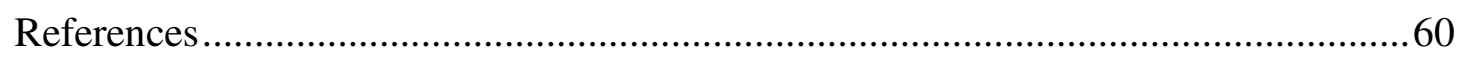




\section{Table of figures and tables}

Chapter 1: Plant community assembly in a New Zealand forest: Driven by determinism or randomness?

Table 1. (A) List of observed adult species ant their presence and abundance on plots and aspect respectively. (B) List of presence and abundance of observed seedlings on

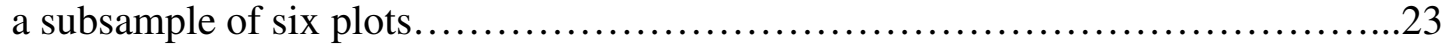

Figure 1. Patterns in species richness for adults...............................26

Figure 2. Patterns in species richness for seedlings........................... 27

Figure 3. Patterns of abundance.............................................28

Figure 4.Observed abundance of each species against the observed abundance of all

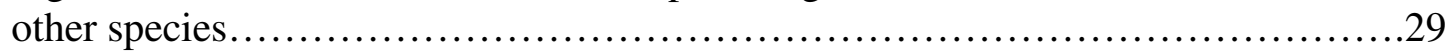

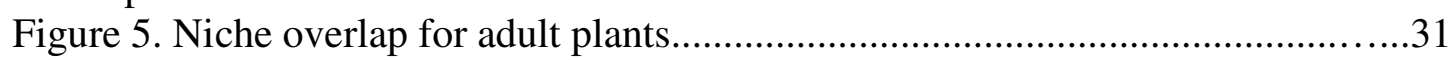

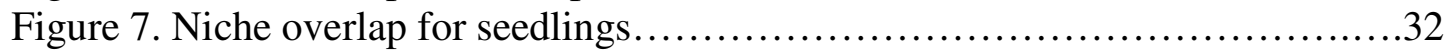

Chapter 2: Relationship between a plant trait and environmental conditions in a New Zealand forest.

Figure 1. Average LMA against average height..............................52

Figure 2. Mean LMA $(\mathrm{g} / \mathrm{m} 2)$ against mean PC1 .................................53

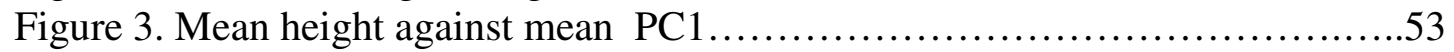

Table 1. Multiple regression for average LMA of each species...................55 
This thesis is divided into two related studies; bellow is a brief introduction of each of the studies conducted.

\section{Brief introduction study 1: Plant community assembly in a New Zealand forest: Driven by determinism or randomness?}

Community assembly provides a conceptual foundation for understanding the processes that determine which and how many species can live in a particular locality.

It has been suggested that various factors, including niche differentiation mediated by competitive trade-offs, frequency dependence resulting from speciesspecific pests, recruitment limitation due to local dispersal and a speciation-extinction dynamic equilibrium mediated by stochasticity play a role in shaping community level properties such as species-area curves, relative species abundance and spatial patterns of species occupancy (Chaves et al. 2002). However, "The unified neutral theory of biodiversity and biogeography" (Hubbell 2001) provides a different explanation for how communities assemble and change overtime. The unified theory builds on the foundation of the original theory of island biogeography. The hypothesis of functional equivalence is the cornerstone of neutral theory. It states that trophicaly similar species are, at least to a first approximation, demographically identical on a per capita basis in terms of their vital rates, of birth, death, dispersal and even speciation (Hubbell 2005).

This study will look at plant community assembly in a New Zealand forest. The aim is to answer the question: Is plant community composition deterministically or stochastically determined in a New Zealand forest? 


\section{Brief introduction study 2: Relationship between a plant trait and environmental conditions in a New Zealand forest}

Leaf mass per area (LMA) is one of the most widely researched plant traits. LMA refers to leaf dried weight divided by its fresh area. Because LMA indexes so much information of ecological importance it is of high interest for plant ecologists and ecophysiologists (Lusk et al. 2008).

Environmental conditions have a strong influence on plant functional traits such as wood density (Thomas et al. 2007) and leaf size (Poorter \& Rozendaal 2008). This environmental influence can be on a large scale (globally) or smaller scale (locally), such as within a forest or reserve. Environmental conditions differ between forest floor and canopy (i.e. vertical variation) and at different locations within the same forest (i.e. horizontal variation) (Chazdon \& Fletcher 1984; Oshima et al. 1997). Research shows that many plant traits tend to co-vary with environmental conditions (Ellsworth \& Reich 1993; Anten \& Werger 1996).

Much study in community ecology focuses in how environmental conditions can affect individuals within a community (Yanez-Espinosa et al. 2003; Valladares et al. 2000; Osada et al. 2001). The relationship between environment and plant form has played a central role in plant ecology and convergent evolution (Ackerly et al. 2002). The aim of this research is to test if there are relationships among species between a plant trait (LMA) and environmental conditions (vertically and horizontally) in a New Zealand forest. 


\title{
Chapter 1: Plant community assembly in a New Zealand forest: Driven by determinism or randomness?
}

\begin{abstract}
Ecological community assemblage is perhaps one of the most important concepts in ecology. One of the primary focuses of studying community assembly is to understand what drives community composition. For over a century it has been debated whether determinism or stochasticity is the main driver of community assemblage. The present study used null models to test whether a plant community in a New Zealand forest was assembled deterministically or stochastically. Abundance of adult species was recorded in thirty $30 \mathrm{~m}$ x $30 \mathrm{~m}$ plots at Otari Wilton's Bush. In a subsample of six plots, the abundance of seedling species was also recorded. Null models for species co-occurrence, species richness, species abundance and niche overlap were used in order to decide how plant communities assemble. Analyses were carried among plots for adults and seedlings. There was evidence of both determinist and stochasticity in some aspects of community assembly for both adults and seedlings. Results therefore suggest a pluralistic approach should be used in order to explain plant community patterns at Otari Wilton's Bush.
\end{abstract}




\section{Introduction}

Plant community assemblage is perhaps one of the most import concepts in ecology. One of the primary focuses of studying plant community assemblage is to understand the main drivers of community composition (Laughlin \& Abella 2007). There are two primary reasons for why it is important to understand plant community assemblage (Finegan 1984); firstly the concept is valuable in the development of ecology as a science and for the development of programmes for the conservation and exploitation of biological resources. Secondly, it is a controversial issue between holism (the view emphasizing unity and integration of nature) and reductionism (in which chance and Darwinian interpretations dominate).

Changes in plant communities over time have been observed for over 2000 years as the earliest documentation of vegetation changes date from $300 \mathrm{BC}$ (Walker \& del Moral 2003). Although changes in vegetation community have been well documented in the 1800 's, theories relating to how changes occur began arising in early 1900's with the publication of Plant Succession: An Analysis of the development of vegetation, by Clements (1916).

Clements (1916) suggested a deterministic unidirectional approach where ecological community is viewed as a superorganism whose member species were tightly bound together now and in their common evolutionary history. Therefore, according to Clements community cannot exist if one of those members is missing. In contrast to Clements description of a community as a superorganism, Gleason (1926) published "The individualistic concept of the plant association", suggesting that in order to study changes in community composition an individualistic, reductionist approach should be used. Gleason focused on the distribution of individual species rather than generalizing across species and patterns instead of processes. Gleason was 
the first to note that, temporally and spatially, each assemblage of species was independent of other assemblages.

Gleason's individualistic concept saw the relationship between coexisting species as a result of similarities in their requirements and tolerances (and partly the result of chance). Therefore, community boundaries need not to be sharp, and associations of species would be much less predictable than one would expect from the superorganism concept.

Although Clementian and Gleasonian views on succession and community assembly arose in the same era, Gleason was overlooked and Clementian views were the focus of studies for over 50 years (Walker \& del Moral 2003), perhaps due to the compelling arguments used in his 1916 book and 1936 paper (Walker \& del Moral 2003).

Following Gleason and Clements, there has been much development in the area of community assembly and the great majority of studies focused on plants communities (Connell \& Slatyer 1977). Egler (1954) recognized two principles involved in vegetation development while studying abandoned agricultural lands; Relay Floristic and Initial Floristic Composition. Relay Floristic, suggests that plants arrive at the new site, ousting its predecessor and preparing the site for the next species until it has ousted itself (this model was later on also described by Connell \& Slatyer (1977)). However, Relay Floristic is considered to be only a minor principle by Egler (1954). Therefore, Initial Floristic Composition, which refers to that element which arrives first at the newly created site (e.g. clearing by disturbance or in this case, clearing for farm land) is more important in dictating the outcome of succession, and ultimately the final composition of the community. Connell \& Slatyer (1977) added more factors to the debate by recognizing that not only competitive interaction 
between plants is important, but also interactions with herbivores, predators and pathogens.

Another factor which influences plant communities is plant strategies for acquiring and maintaining nutrients in a nutrient limited and nutrient rich environment respectively. There is a dichotomy in ecology regarding such plant strategies described by Grime (1974) and Tilman (1985). Both attempt to unify contrasting theories regarding the construction of plants, their interaction with the environment and the assembly of communities (Craine 2005).

Grime (1974) theory covers the roles of competition, nutrient stress and disturbance and their predominance as well evolution of species and assembly of communities. According to Grime (1974), competition for nutrients is a race to produce roots in areas of high nutrient availability, but low root occupancy, thus allowing a plant to pre-empt nutrients from competitors. At the beginning of a growing season, plants race to acquire a general pulse of nutrients throughout the soil volume where roots have not yet explored. Once widespread availability declines, competition is minimal until a new pulse initiates a new race. This seems reasonable in situations where nutrient availability is high for short periods of time, or in small patches, however nutrients still limit production. This generally occurs in environments with heterogeneous distribution of nutrients, but is unusual in environments where nutrients are uniformly distributed.

Grime (1974) suggested that the mechanism plants adopt when competing for light is the production of leaves above its competitors. With a uni-directional light source, pre-empting the supply becomes a race to the top. Grime proposed that shade adapted plants do not acquire light better when light levels are low, but conserve their 
carbon or energy better. For the purposes of assembly of communities, the importance of competition is greater in high rather than at low nutrient supply.

Tilman (1985) studied an area with sites derived from the same glacial outwash sand. The grassland species were primarily limited by nitrogen $(\mathrm{N})$, which had been reduced by agriculture to approximately $50 \%$ of its original value. Over time, soil $\mathrm{N}$ content increased in the abandoned fields, leaving a successional gradient of young fields with low soil $\mathrm{N}$ content, older fields with higher soil $\mathrm{N}$ content and native savannas and forest with the highest soil $\mathrm{N}$ content. Tilman (1985) hypothesised that the successional sequence was driven by changes in soil nutrients which is influenced by the ratio of nutrient and light supply. It was suggested that plants that occupied low $\mathrm{N}$ :light environments were the better competitors for $\mathrm{N}$ and those that occupied high $\mathrm{N}$ :light environment were better competitors for light. This was later found not to be the case as, in an analyses of four years of growth of plants in natural assemblages that had been fertilized at different rates with $\mathrm{N}$, an early successional species, which had one of the highest relative growth rates in soils with low $\mathrm{N}$ content, dominates at high $\mathrm{N}$ supply and a late successional species, with one of the lowers growth rates in soils with low $\mathrm{N}$ soils, dominated plots with low $\mathrm{N}$ addition rates (Craine 2005).

Currently, there are at least four prominent research speciality areas that study vegetation changes/community assembly: succession ecology, invasion biology, gap/patch dynamics and global change effects on plant communities (Davis et al. 2005). The underlying processes studied in each of these areas are basically the same: First, colonization, establishment, turnover, persistence and spread. Secondly, influences by disturbance and/or changes in interactions with species from other trophic levels. Thirdly, local and long distance dispersal events. Fourth, facilitation 
and inhibition, and fifth, how changes in community composition affect and are affected by ecosystem processes (Davis et al. 2005).

As mentioned before, Clement's view on community assembly was widely accepted for around 50 years after its release, while Gleason was neglected. However, Gleason's views gained more attention and this can be seen by the number of recent studies focusing on Gleason's view while studying community assembly (Wilson \& Chiarussi 2000; Anderson 2007). Gleason's view of plant community also gave origin to different theories such as Hubbel and the neutral theory of ecology (Lortie et al. 2004). Community assembly provides a conceptual foundation for understanding the processes that determine which and how many species can live in a particular locality. There are two different views on how this assemblage of species occurs (Chase 2003):

1) There is a one-to-one match between environment and community. So, regardless of the historical order in which species invade, if all species have access to a given community, composition should converge towards a single configuration in localities with similar environmental conditions (single stable equilibrium).

2) Depending on the order in which species enter a locality can lead to different final community composition, even when the environment in each locality is similar and all species have access to the locality (multiple stable equilibria).

It has been suggested that niche differentiation mediated by competitive tradeoffs; frequency dependence resulting from species-specific pests; recruitment limitation due to local dispersal and a speciation-extinction dynamic equilibrium mediated by stochasticity play a role in shaping community level properties such as species-area curves, relative species abundance and spatial patterns of species occupancy (Chave et al. 2002). However, "The unified neutral theory of biodiversity 
and biogeography" (Hubbell 2001) provides a different explanation on how communities assemble and change overtime. The unified theory builds on the foundation of the original theory of island biogeography. The hypothesis of functional equivalence is the cornerstone of neutral theory. It states that trophicaly similar species are, at least to a first approximation, demographically identical on a per capita basis in terms of their vital rates, of birth, death, dispersal and even speciation (Hubbell 2005).

According to Hubbell (2001), external factors to the community play a minimal role in community assemblage and composition. There are some characteristics of the neutral theory which make it so unique; firstly interactions among species are assumed to be equivalent on an individual "per capita" basis. Secondly, it is a stochastic theory, based on mechanistic assumptions about the processes controlling the origin and interaction of biological populations at the individual level; thirdly, it is a sampling theory (was built up upon the sampling theory of selectively neutral alleles in population genetics) and fourthly it is a dispersal-assembled theory, meaning that dispersal is assumed to have a leading role in structuring ecological communities (Alonso et al. 2006). Therefore, by starting with null models, more variables can be added to the study (Zobel 1992). Yet, some suggest that Hubbell's theory may not describe the real world as it assumes density dependence and habitat specialization (Ricklefs 2006). Hence, neutral models view all species as equal or at least as near neutral, but niche-based models ascribe particular properties to species (Lortie et al. 2004).

Much research has been done on plant community assembly, and the main focus of the studies is to test whether plant communities are assembled deterministically or stochastically (Collins and Glenn 1991; Leibold and McPeek 
2006; Ribichich 2005). The issue however remains far from resolved as there continues to be little consensus among studies. If stochasticity is the main driver of community assembly, a random number of co-ocurring species is expected (Gleason 1926; Connor \& Simberloff 1979; Hubbell 2001). If determinism is found to be the main driver of community assembly and competition prevails, a lower number of coocurring species than expected is likely to be observed (Lieberman \& Lieberman 2007; Perry et al. 2009), whereas, if facilitation prevails, a higher number of coocurring species than expected is likely (Cavieres et al. 2002; Cavieres \& Badano 2009).

This study will look at plant community assembly in a New Zealand forest. The aim is to answer the question: Is plant community composition deterministically or stochastically determined in a New Zealand forest?

\section{Methods}

\section{Study site, field sampling and species}

Otari-Wilton's Bush $\left(41^{\circ} 14^{\prime} \mathrm{S}, 174^{\circ} 45^{\prime} \mathrm{E}\right)$ is located just within Wellington city limits at the southern tip of the North Island of New Zealand, and encompasses approximately 100 hectares of native forest. The reserve is situated 70-280 meters above sea level and the soil is comprised of stoney colluvium of greywacke parent material. Average annual rainfall totals 1,240 millimetres and average daily temperatures range from $20^{\circ} \mathrm{C}$ in summer to $7^{\circ} \mathrm{C}$ in winter (Council 2007). The vegetation is classified as coastal conifer-broadleaved forest, whose vertical structure is highly complex and similar to most tropical forests (Dawson \& Lucas 2000) .It has a fairly continuous canopy, which is frequently interrupted by canopy gaps and canopy emergent tree species. A dense community of shrubs and tree ferns occurs 
beneath the canopy (Blick et al. 2008) .Lianas and epiphytes are also abundant (Burns and Dawson, 2005) . Dysoxylum spectabile is the dominant canopy-forming species, alongside Melicytus ramiflorus, Corynocarpus laevigatus and Elaeocarpus dentatus. Macropiper excelsum and Geniostoma rupestre are the most common subcanopy shrubs. Emergent trees include Dacrydium cupressinum, Beilschmedia tawa and Knightia excelsa. Burns (2007) gives a detailed inventory of the woody plant community.

Thirty 30m x 30m plots were surveyed within the reserve (following Marjot 1992). The plots encompassed a range of environmental conditions which were decided upon before data collection started as it was desired to cover plots facing different aspects (N, S, E, W and in betweens). Once the locations were chosen plots were randomly placed within the location.

In each plot abundance of adult woody vascular plant species was recorded. Adults in this study are defined as individuals capable of reproducing. Factors such as presence of fruit and/or flowers or evidence of such were used in deciding whether or not to include an individual in the study. Out of the 30 plots, a subsample of six plots was also selected. In this subsample, abundance of seedlings was recorded. Seedlings were defined as individual plants between $0.1 \mathrm{~m}$ and $1 \mathrm{~m}$ in height which were not sexually mature at the time of the survey. While there is some overlap in the definition of adult plant and seedlings, as some plants smaller than $1 \mathrm{~m}$ may be sexually mature, only one individual (Geniostoma rupestre) was smaller than $1 \mathrm{~m}$ and sexually mature, thus, this individual was only included in the adult analyses. 


\section{Data analysis}

\section{Negative Co-occurrence patterns}

Co-occurrence patterns were analyzed by using the software EcoSim (Gotelli \& Entsminger 2007). For the analyses a matrix of 35 rows (one for each species) and 30 columns (one for each plot) was generated for adult plant. For seedlings a matrix of 13 rows (one for each species) and 6 columns (one for each plot) was generated. Three different metrics were used in order to determine if species co-occurrence patterns were randomly or deterministically shaped; the c-score index, the checkerboard score and the number of unique species combinations. For the tests, observed values were compared statistically to the distribution of expected values generated by the null model. The c-score index provides a comparison of species cooccurrence among the data, the checkerboard score provides a score based on species that never co-occurred and the number of unique species combinations is a count of all species pairs that co-occurred with one another.

These tests can be used to provide evidence for whether communities are deterministically or randomly assembled. If determinist is the main force shaping communities, higher C-scores, fewer unique species combinations, and more checkerboard species pairs should be expected under the null model (Lester et al. 2009).

\section{Checkerboard species pair analysis}

Once the count data was entered in the matrix it was transformed into binary data ( 1 when the species is present in the sample and 0 when it is absent); thus, this test uses the presence/absence of species rather than their abundance in order to provide results. Diamond (1975) suggests that a checkerboard distribution is the 
simplest way to provide evidence for competitive exclusion. A checkerboard unit is any submatrix on the form:

$\left[\begin{array}{l}\ldots 1 \ldots 0 \ldots \\ \ldots \ldots \ldots \ldots \\ \ldots 0 \ldots 1 \ldots\end{array}\right]$

Based on the matrix above, the number of checkerboard units (CU) for each species pair was calculated according to the following formula:

$\mathrm{CU}=\left(\mathrm{r}_{\mathrm{i}}-\mathrm{S}\right)\left(\mathrm{r}_{\mathrm{j}}-\mathrm{S}\right)$

where $\mathrm{S}$ (columns) is the number sites containing both species.

$r_{i}$ and $r_{j}$ are the row totals for species $i$ and $j$.

EcoSim uses the Stone and Robert (1990) C-score. This score measures the average number of "checkerboard units" between all possible pairs of species. The Cscore was calculated as the average of all possible checkerboard pairs which occur at least once in the matrix. Therefore, the tendency for species to not occur together was given by the C-Score.

The number of checkerboard species pairs follows directly from Diamond's (1975) assembly rules analysis (see Gotelli et al. 1997 for more on the subject). For this index, the rows of the matrix are scanned by EcoSim (Gotelli \& Entsminger 2007), and the numbers of species pairs that never co-occur in any site are tabulated. Count data is also transformed in binary data.

For the number of species combinations, the columns of the presence-absence matrix are scanned and the number of unique species combinations that are 
represented at different sites are tracked. For an assemblage of a given number of specie (n), there are $2^{\mathrm{n}}$ possible species combinations, including the combination of no species being present.

\section{Species richness and abundance}

To test for the relationship between species richness and overall abundance of individuals, rarefaction was used. Rarefaction estimates species richness on a per individual basis; that is, for a determined number of individuals sampled it gives an expected number of species based on a null model (Gotelli \& Grave 1996; Gotelli \& Colwell 2001). Rarefaction values and curves were generated by using Rarefact 1.0. Separate rarefaction curves were generated for adult plants and seedlings.

By calculating the differences between Observed $(\mathrm{O})$ and expected $(\mathrm{E}$, given by rarefaction) values it was possible to plot a graph of residuals in order to observe if species abundance are higher, lower or the same than expected under the null model. The null model calculates an expected number of species given a total abundance. However, differences between observed and expected values increase passively with the magnitude of expected values. Therefore, in order to control for this effect, the difference was divided by expected values $\left.\left[(\mathrm{O}-\mathrm{E}) \mathrm{E}^{-1}\right)\right]$, which results in an unbiased estimate of deviations from expected species richness values (Lester et al. 2009).

To test whether differences from expected species richness were significantly different from the null model, general linear models were used. Standardized differences from expected species richness values were included as dependent variables, and total plant abundance was treated as a covariate. Separate analyses were 
conducted for plot, aspect and seedlings. Analyses were conducted using SPSS 16 statistical software.

Graphs were also generated by plotting the observed abundance of each species against its expected values (intraspecific), this provides an indicative whether abundance of individuals follow null model expectations. Also, abundance of each individual species in each plot was plotted against the abundance of all other individuals (interspecific) in order to provide information whether abundance of each species is influenced by the abundance of all other species.

To test whether observed abundance of individuals (both intra and inter specifically) differed from expected, a chi-square test was conducted. Expected (E) number of individuals was calculated by multiplying the total for each row by the total for each column, divided by the total for the table. The following formula was then applied to calculate the chi-square value:

$$
\chi_{c}^{2}=\sum \frac{\left(\mathbf{O}_{i}-E_{i}\right)^{2}}{E_{i}} \quad \begin{aligned}
& \text { Where: } \\
& O=\text { observed values } \\
& \text { E }=\text { expected values }
\end{aligned}
$$

\section{Niche overlap}

Niche overlap was measured by using EcoSim (Gotelli \& Entsminger 2007). In this study, the analysis looked at the overlap in shared locations rather than resources themselves. Firstly, to test for differences in niche overlap, the Czekanowski Index (Feinsinger et al. 1981) was used. Czekanowski Index is a symmetric indices meaning the overlap of species 1 on species 2 is equivalent to the overlap of species 2 on 1 . Niche overlap is given as a number which varies between 0 (no overlap) and 1 (complete overlap) and is attained by the following formula: 


$$
\begin{array}{ll}
O_{12}=O_{21}=1.0-0.5 \cdot \sum_{i=1}^{n}\left|p_{1 i}-p_{2 i}\right| & \begin{array}{l}
\text { Where: } \\
\mathrm{O}=\text { Observed index } \\
\mathrm{j}=1 \text { to } \mathrm{n} \text { resource states } \\
\mathrm{p}_{1 \mathrm{j}}=\text { the proportional use of resource state } \mathrm{j} \\
\text { by species } 1 .
\end{array}
\end{array}
$$

EcoSim (Gotelli \& Entsminger 2007) calculates proportional values by summing up the row totals, and then dividing each entry in the matrix by its row sum. Thus, the $\mathrm{p}_{\mathrm{ij}} \mathrm{s}$ will sum to 1.0 for each species. By running 1000 simulations and comparing simulation values (null model) against the observed value, it was possible to imply whether there is evidence of overlap in space utilized by plant species.

In this study some species were significantly more abundant than others (see table 1), and some plots had a higher abundant of individuals than others. In order to control for abundance, data was standardized before being entered and analysed in EcoSim (Gotelli \& Entsminger 2007). Similarly to what EcoSim (Gotelli \& Entsminger 2007) does to the data before running the Czekanowski Index, each entry in the matrix was divided by its row total and multiplied by 100 . Therefore, proportions were used in the analyses and for all plots, proportions (abundance) totalized 100 .

\section{Results}

A total of 35 adult woody plant species were found amongst the 30 plots. For seedling, the number of species was 13 . The number of individuals varied greatly among species for adult plants. Table 1 displays a detailed inventory of the abundance of all adults (A) and seedlings (B) species. 
Table 1. (A) List of observed adult species and their presence and abundance on plots and aspect respectively. (B) List of presence and abundance of observed seedling species on a subsample of six plots.

\begin{tabular}{|c|c|c|}
\hline $\begin{array}{l}\text { (A) } \\
\text { Adult species }\end{array}$ & $\begin{array}{c}\text { Presence } \\
(\mathrm{n}=30)\end{array}$ & $\begin{array}{l}\text { Abundance } \\
\text { range }\end{array}$ \\
\hline Disoxylum spectabile & $63 \%$ & $1-61$ \\
\hline Beilschmiedia tawa & $77 \%$ & $2-23$ \\
\hline Geniostoma rupestre var. & & \\
\hline lingustrifolium & $100 \%$ & $2-31$ \\
\hline Knightia excelsa & $70 \%$ & $1-12$ \\
\hline Pseudopanax arboreus & $13 \%$ & $1-3$ \\
\hline Corynocarpus laevigatus & $27 \%$ & $1-8$ \\
\hline Pittosporum tenuifolium & $3 \%$ & 2 \\
\hline Carpodetus serratus & $3 \%$ & 7 \\
\hline Myrsine australis & $27 \%$ & $1-4$ \\
\hline Elaeocarpus dentatus & $43 \%$ & $1-10$ \\
\hline Hedicaria arborea & $13 \%$ & $3-6$ \\
\hline Melicytus ramiflorus & $90 \%$ & $2-34$ \\
\hline Dacridium cupressinum & $27 \%$ & $1-2$ \\
\hline Aelectrion excelsum & $10 \%$ & $2-8$ \\
\hline Kunzea ericoides & $3 \%$ & 2 \\
\hline Prumnopitys ferruginea & $27 \%$ & $1-5$ \\
\hline Cyathodes fasciculata & $3 \%$ & 3 \\
\hline Coprosma robusta & $20 \%$ & $1-6$ \\
\hline Macropiper excelsum & $77 \%$ & $1-28$ \\
\hline Hoheria populnea & $7 \%$ & $1-3$ \\
\hline Brachyglottis repanda & $23 \%$ & $1-8$ \\
\hline Metrosideros robusta & $7 \%$ & 1 \\
\hline Olearia rani & $7 \%$ & 2 \\
\hline Laurelia novae-zelandiae & $13 \%$ & 1 \\
\hline Aristotelia serrata & $3 \%$ & 2 \\
\hline Pittosporum eugenioides & $13 \%$ & $1-2$ \\
\hline Podocarpus totara & $7 \%$ & 1 \\
\hline Prumnopitys taxifolia & $7 \%$ & $1-3$ \\
\hline Pennantia corymbosa & $3 \%$ & 1 \\
\hline Elaeocarpus hookerianus & $3 \%$ & 1 \\
\hline Schefflera digitata & $3 \%$ & 4 \\
\hline Dacrycarpus dacrydioides & $7 \%$ & 1 \\
\hline Coprosma areolata & $3 \%$ & 1 \\
\hline Coprosma grandifolia & $7 \%$ & 2 \\
\hline Coprosma lucida & $3 \%$ & 1 \\
\hline
\end{tabular}




\begin{tabular}{lcc}
\hline (B) Seedling species & $\begin{array}{c}\text { Presence } \\
(\mathrm{n}=6)\end{array}$ & $\begin{array}{c}\text { abundance } \\
\text { range }\end{array}$ \\
\hline & & \\
Brachyglottis repanda & $67 \%$ & $1-3$ \\
Coprosma grandifolia & $67 \%$ & 1 \\
$\begin{array}{l}\text { Corynocarpus } \\
\text { laevigatus }\end{array}$ & $83 \%$ & $5-26$ \\
Dysoxylum spectabile & $100 \%$ & $1-28$ \\
Geniostoma rupestre & & \\
var. lingustrifolium & $100 \%$ & $4-17$ \\
Melicytus ramiflorus & $50 \%$ & $1-2$ \\
Aelectryon excelsus & $17 \%$ & 1 \\
Coprosma robusta & $17 \%$ & 1 \\
Knightia excelsa & $33 \%$ & $1-4$ \\
Macropiper excelsum & $83 \%$ & $6-35$ \\
Hoheria ovata & $17 \%$ & 2 \\
Olearia rani & $33 \%$ & 1 \\
Coprosma lucida & $17 \%$ & 1
\end{tabular}

\section{Species co-occurrences}

Different results were observed when looking at species co-occurrence for adults and seedlings. Some evidence for co-occurrence assembly rules was observed on adult plants. The observed c-score (9.60) was statistically significant different from the model expectations among plots (expected $=8.78$, variance $=0.024 ; \mathrm{p}=0.0006$ ) However, for number of pairs checkerboard species (observed $=281$; expected $=$ 293.96, variance $=39 ; p=0.98)$ and number of combinations (observed $=29$, expected $=29.94$, variance $=0.06 ; p=0.99)$ no significant difference between observed values and null models were observed.

When analyzing the seedlings of a subsample of six plots no significant difference was observed between the observed c-score (6) and the mean of simulated indices $($ expected $=5.97$, variance $=0.03 ; p=0.97)$. The number of pairs of checkerboard species also was not statistically significant (observed $=30$, expected $=$ 
27.46 , variance $=2.14 ; \mathrm{p}=0.08)$ and neither was the number of combinations $($ observed $=6$, expected $=5.95$, variance $=0.04 ; \mathrm{p}=0.95)$

\section{Species richness}

When analyzing the deviations (differences between observed and expect) for species richness. For adult plants a significant difference between deviations was observed $\left(\mathrm{F}_{1,22}=10.13 ; \mathrm{p}=0.05\right)$ (figure $1 \mathrm{~A}$ and $\left.1 \mathrm{~B}\right)$. Similar results were also observed for seedlings $\left(\mathrm{F}_{1,4}=13.85 ; \mathrm{p}=0.02\right)$ (figure $2 \mathrm{~A}$ and $\left.2 \mathrm{~B}\right)$. These results suggest that for adult plants and among seedlings, the number of species observed based on the sample size was less than expected by chance under the null model.

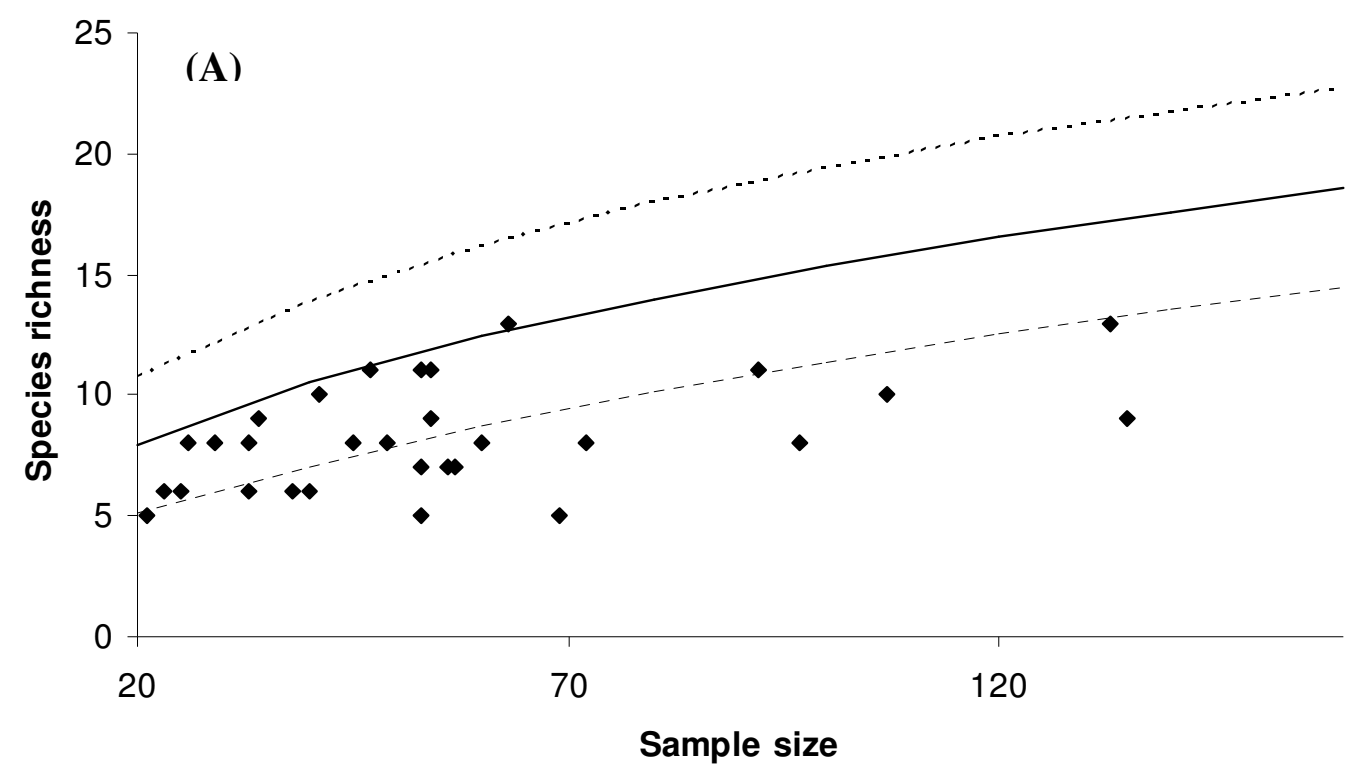




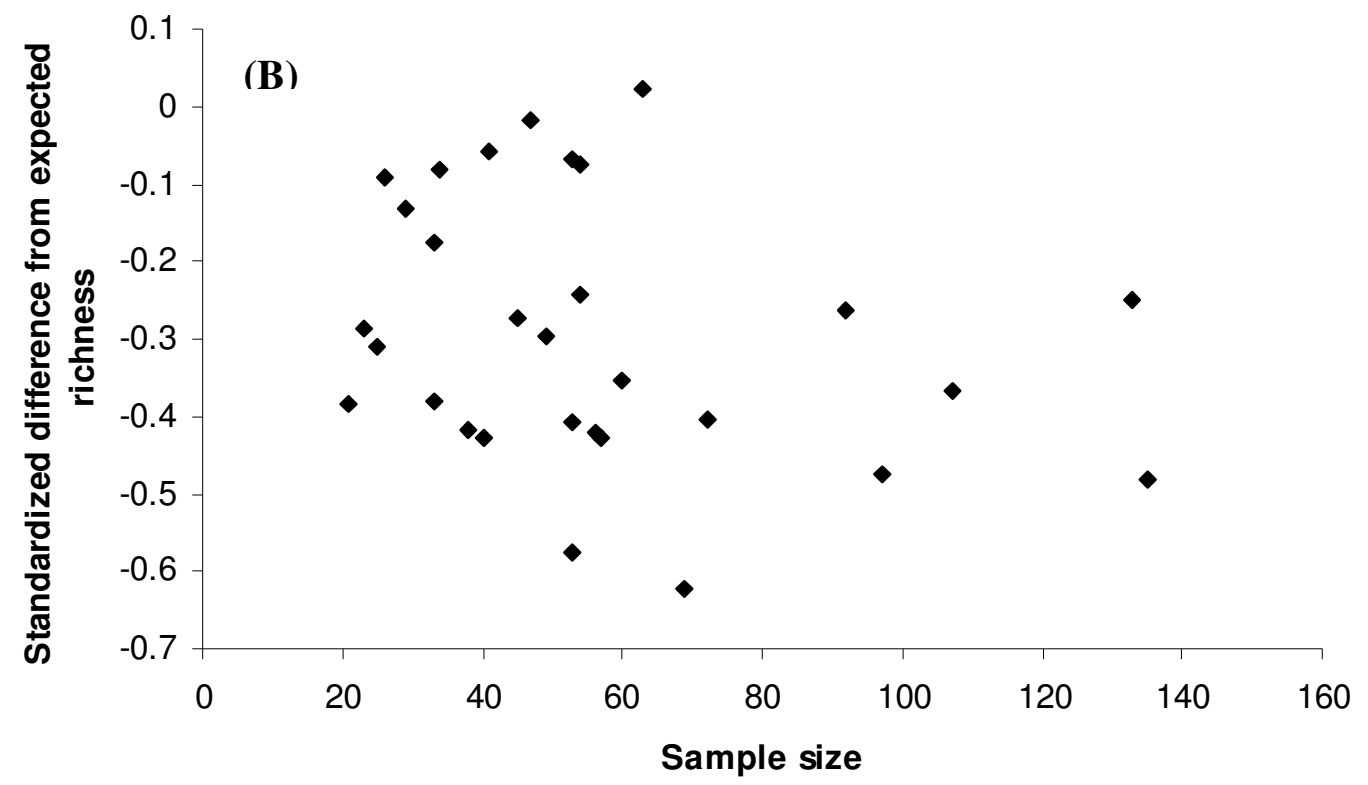

Figure 1. Patterns in species richness for adults. (A) Species richness plotted against observed individuals in each plot. Each point refers to a plot. Solid line is the rarefaction curve which reflects the expected number of species depending on sample size, and dashed lines are $95 \%$ confidence intervals. (B) Deviations from expected richness values $\left[(\mathrm{O}-\mathrm{E}) \mathrm{E}^{-1}\right]$ plotted against sample size. Each point refers to a plot.

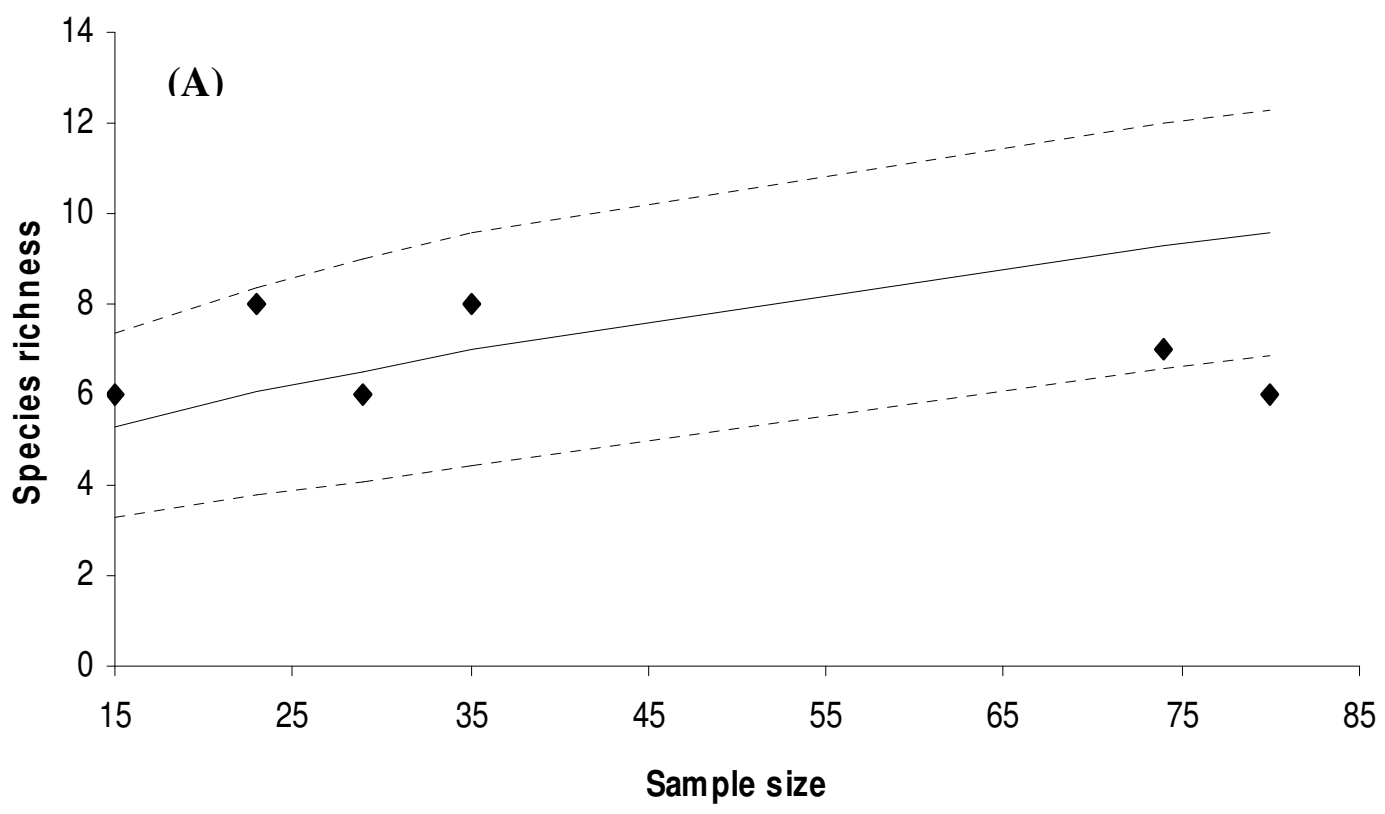




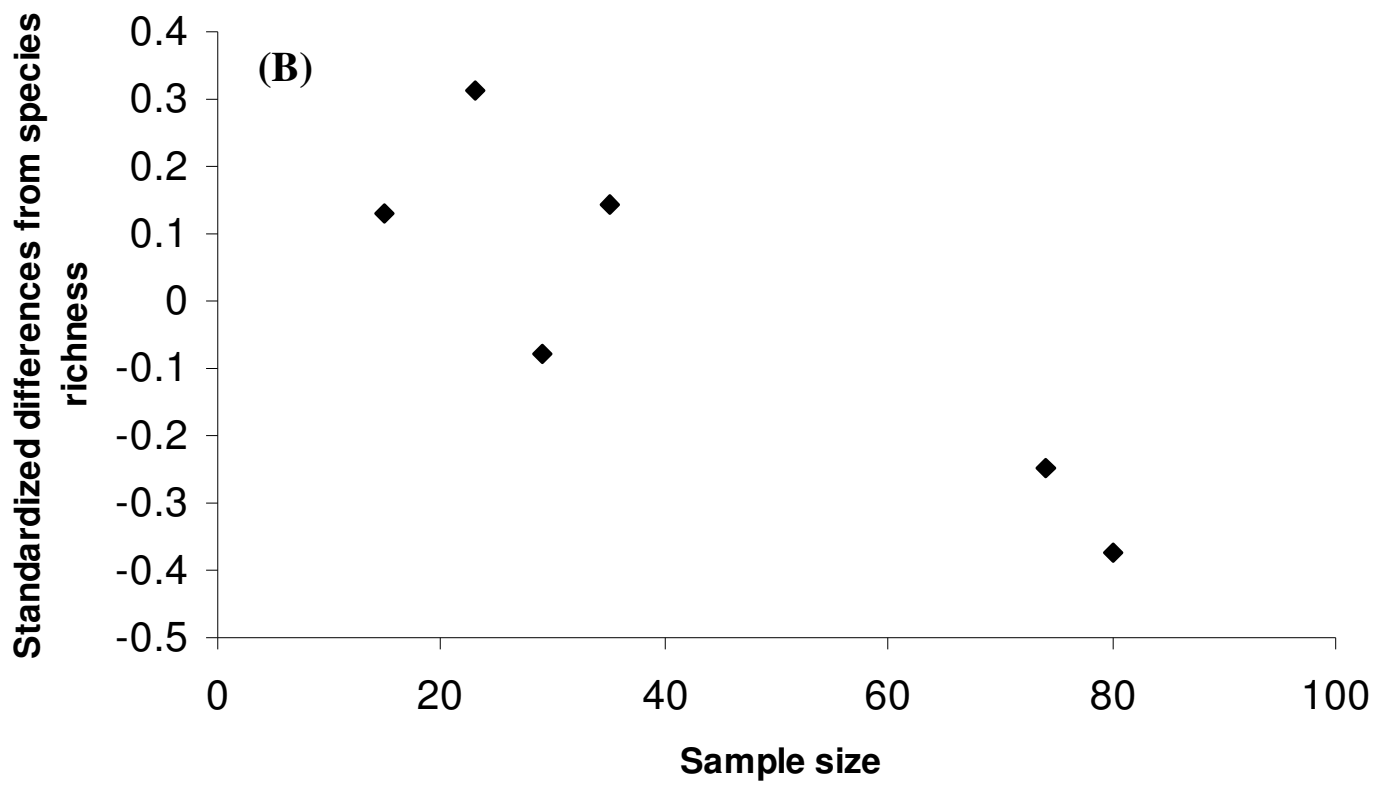

Figure 2. Patterns in species richness for seedlings. (A) Species richness plotted against observed individuals in each plot. Each point refers to a plot. Solid line is the rarefaction curve which reflects the expected number of species depending on sample size, and dashed lines are $95 \%$ confidence intervals. (B) Deviations from expected richness values $\left[(\mathrm{O}-\mathrm{E}) \mathrm{E}^{-1}\right]$ plotted against sample size. Each point refers to a plot.

\section{Abundances}

Abundance of plant species was positively associated with the expectations of the null model for adults $\left(X^{2}=3,767, d f=1 ; p<0.0001\right)($ Fig $3 A)$ and seedlings $\left(X^{2}\right.$ $=151, \mathrm{df}=1 ; \mathrm{p}<0.0001)($ Fig 3B). However, the opposite pattern was observed when plotting abundance of each species against the abundance of all other species in the plot as species abundance tend to decrease with increase in abundance of all other species for adult plants $\left(X^{2}=44,444\right.$ d.f. $\left.=1 ; p<0.0001\right)$ and seedlings $\left(X^{2}=2,682\right.$ d.f. $=1 ; \mathrm{p}<0.0001)$ 

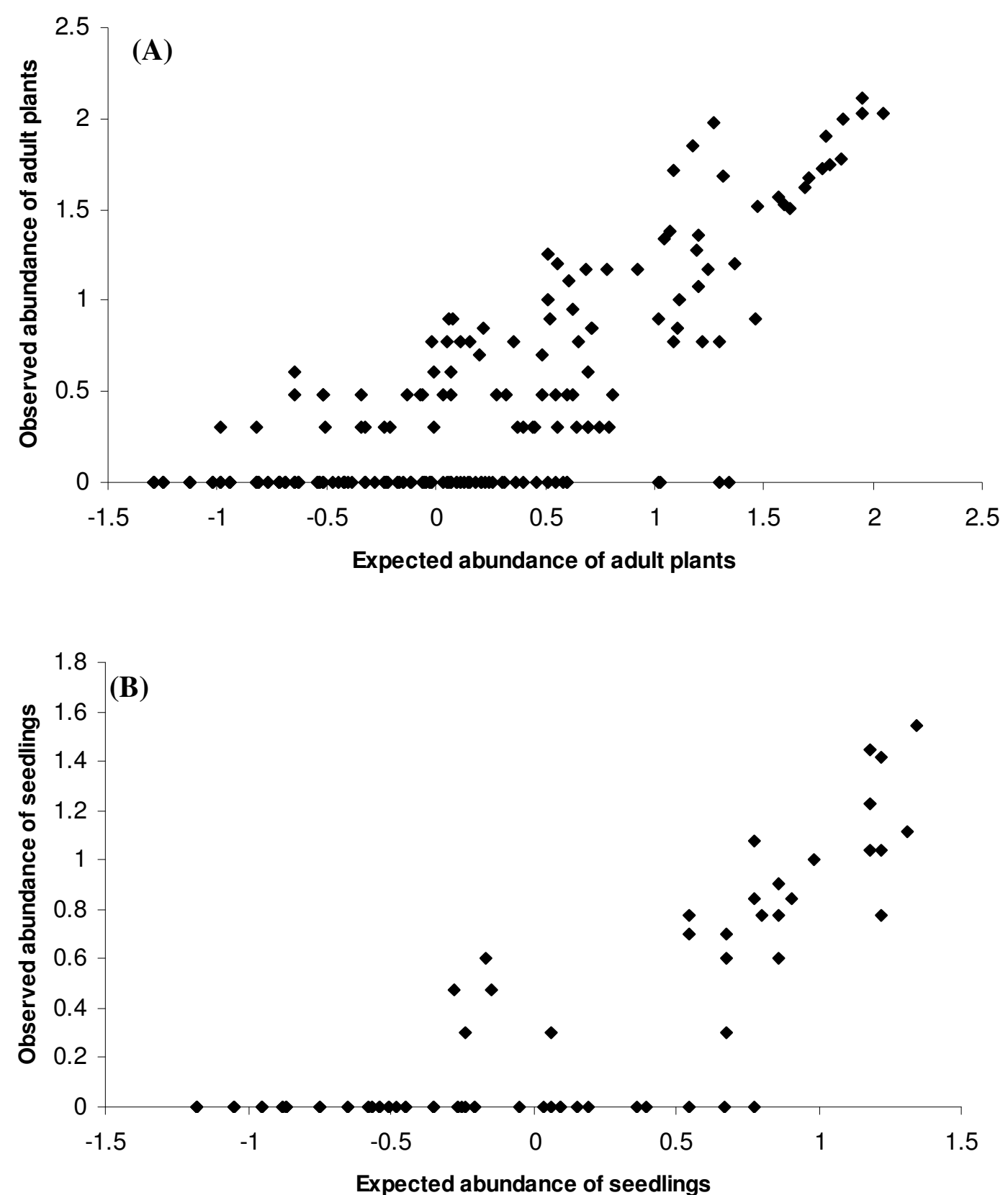

Figure 3. Patterns of abundance. (A) Observed abundance of adult plants plotted against expected number of adult plants for adult plants. (B) Observed abundance of seedlings plotted against expected abundance of seedlings. Note that values for expected and observed abundance are logged. 

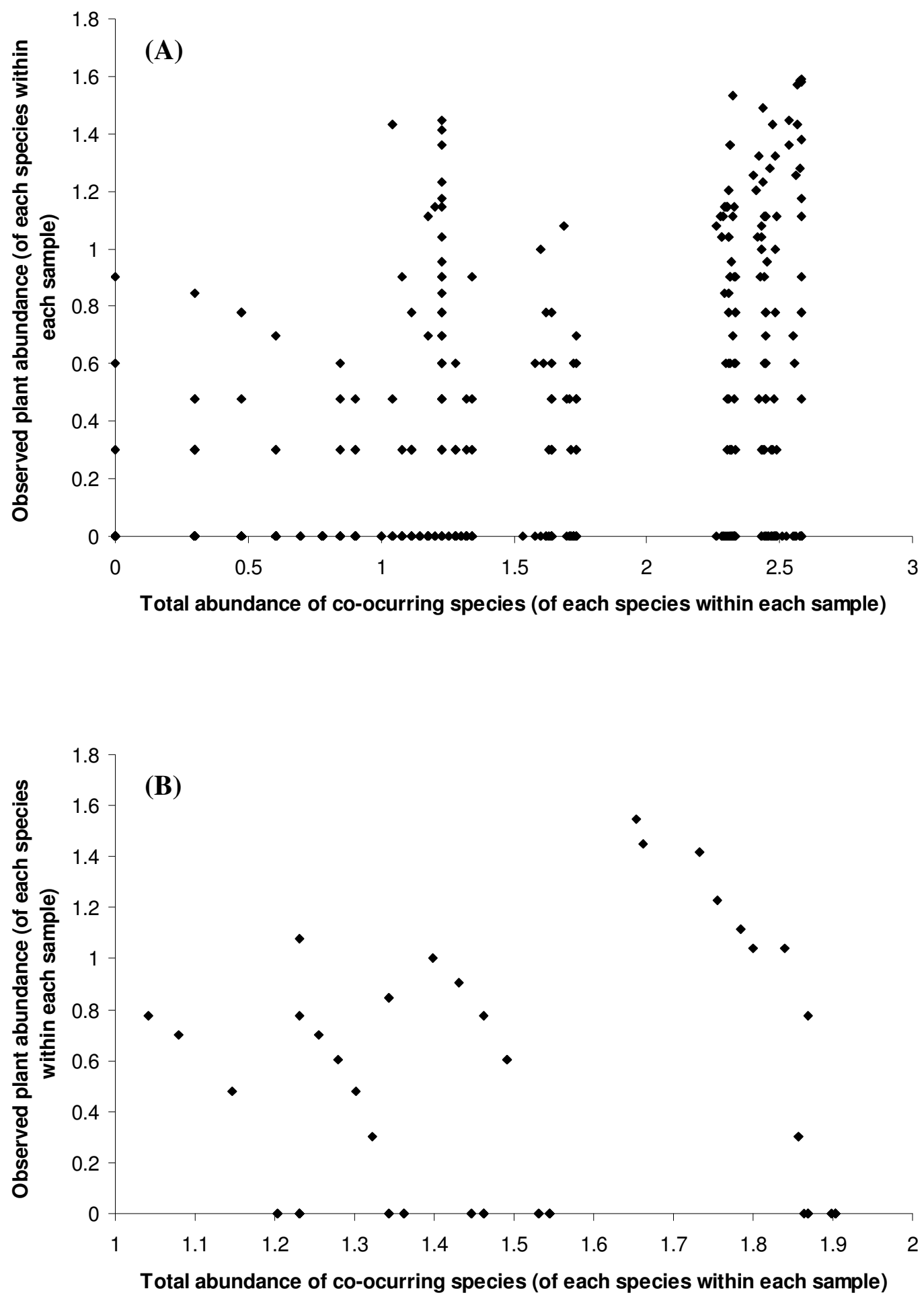

Figure 4. Observed abundance of each species against the observed abundance of all other species. For both scales, observed plant abundance of each species tends to decrease with abundance of all other species present in the plot, adults (A) and juveniles (B). Values are logged. 


\section{Niche overlap}

For adult plants, the observed mean of niche overlap was 0.105 ; when comparing this value with the expected mean under the null model, a significant statistical difference was observed $($ expected mean $=0.082$, variance $=0.00002 ; \mathrm{p}=$ 0.001) (Fig 5A). Similarly, when analysing the observed variances in pairwise niche overlap (0.025), no significant difference was observed against the niche overlap values in the simulated matrices (expected mean $=0.018$, variance $=0.00 ; p=0.008)$ (Fig 5B).

In contrast to results observed in adult plants, randomness seemed to prevail amongst seedlings. Among seedlings, the observed mean of niche overlap was 0.242; when comparing this value with the expected mean under the null model, no significant statistical difference was observed $($ expected mean $=0.258$, variance $=$ $0.0005 ; p=0.737)($ Fig $6 \mathrm{~A})$. For the analysis of the observed variances in pairwise niche overlap (0.063), no significant difference was observed against the niche overlap values in the simulated matrices $($ expected mean $=0.061$, variance $=0.00006$; $\mathrm{p}=0.373)($ Fig 6B).

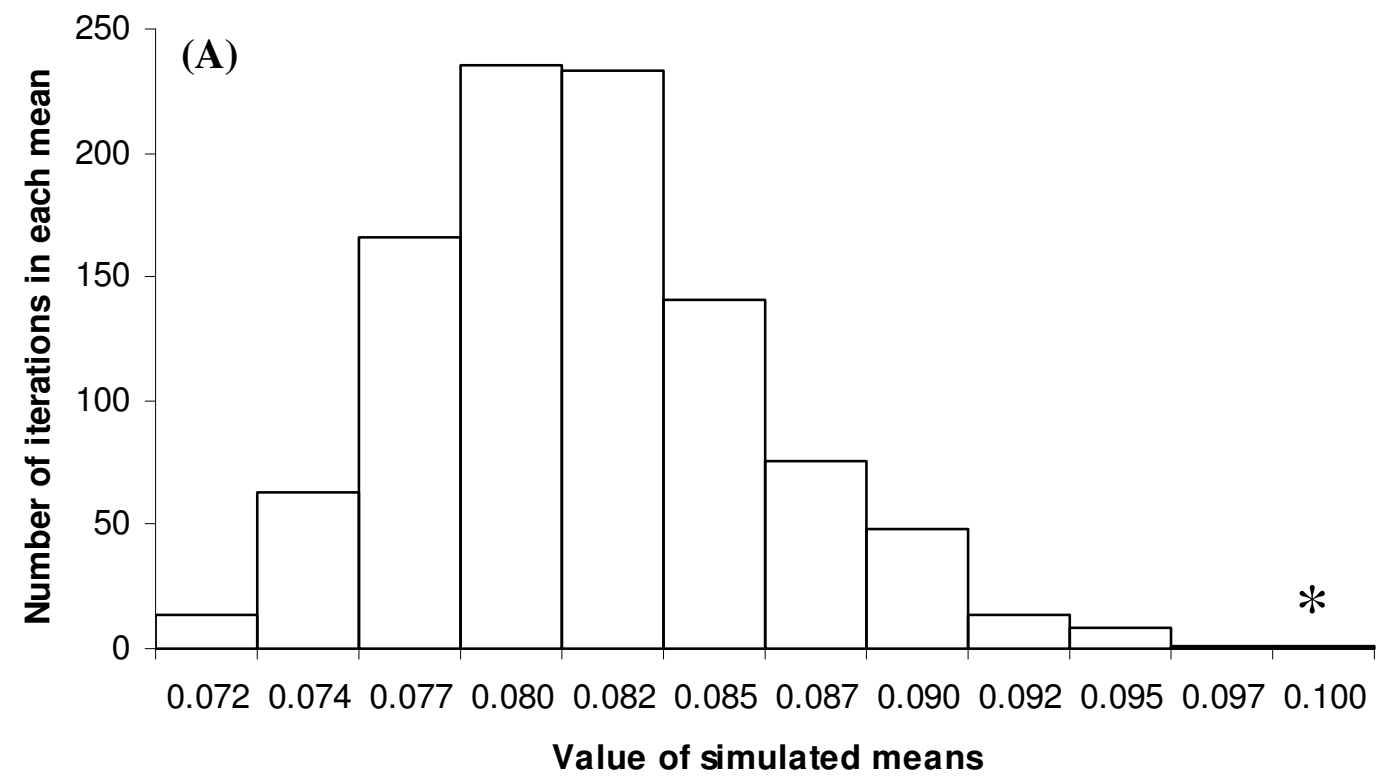




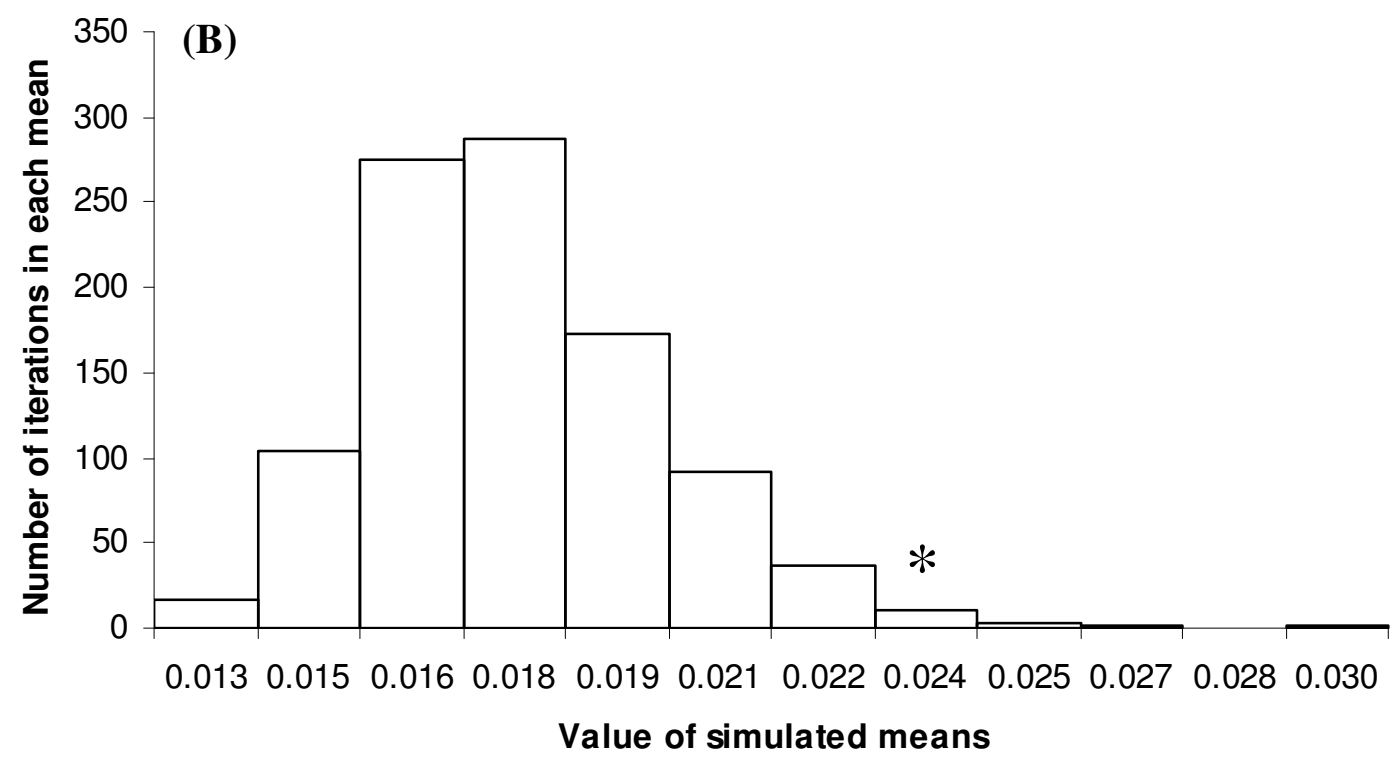

Figure 5. Niche overlap for adult plants. Number of iterations in each simulation plotted against the simulated means. (A) Mean of niche overlap and (B) observed variances in pairwise niche overlap. ${ }^{*}=$ observed mean.

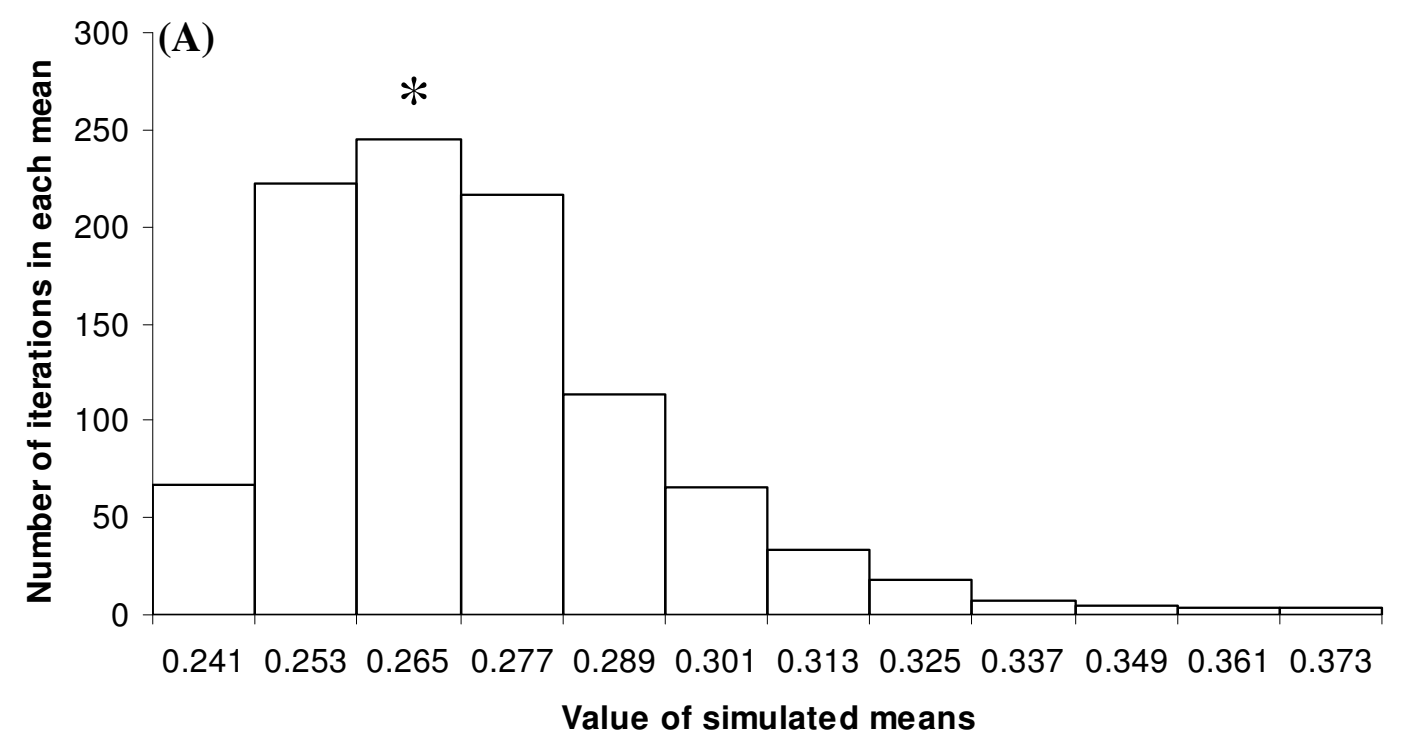




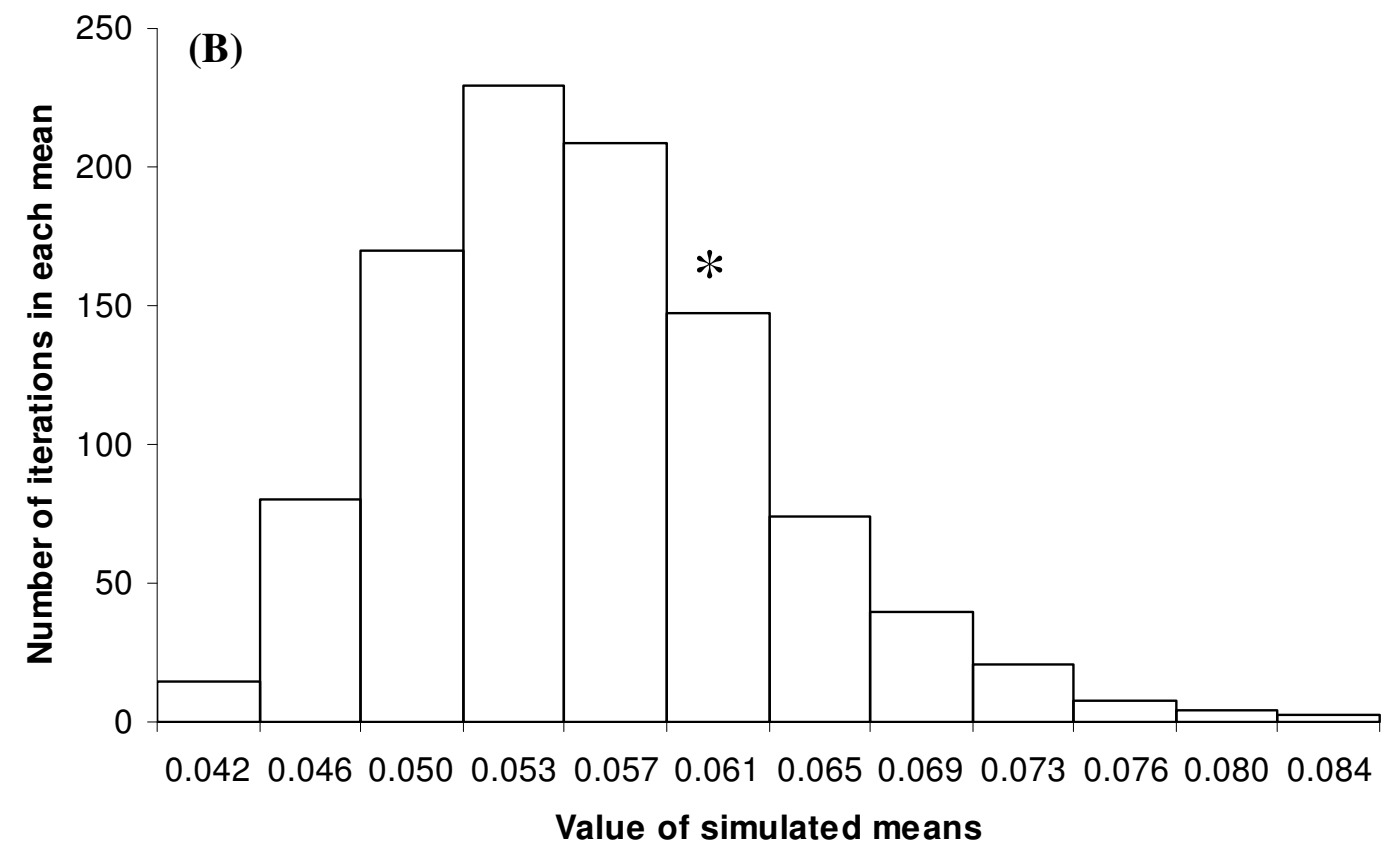

Figure 6. Niche overlap for seedlings. Number of iterations in each simulation plotted against the simulated means. (A) Mean of niche overlap and (B) observed variances in pairwise niche overlap. $*=$ observed mean.

\section{Discussion}

It appears that the adult plant community at Otari Wilton's Bush is assembled by a mix of determinism and stochasticity, whereas, chance appears to be the main factor in the assembly of seedling communities. Co-occurrence results suggest a mix between differences and similarities with the null models for adult plants. For seedlings however, co-occurrence observed in the field fits with the null model expectations. Species richness was less than expected under the null model for both adult plants and seedlings. Abundance analysis showed that for adult species and seedlings, abundance was positively associated with null model expectations. Observed means of niche overlap for adult plants significantly differed from null 
model expectations, however, for seedlings, field observations fitted with the null model.

Co-occurrence analysis results displayed mixed support for community assembly rules. For adult plants, a non random co-occurrence of species was observed. This deterministic co-occurrence may be an indicator of interspecific competition, which occurs in many plant communities (Aguiar et al. 2001; Huckle et al. 2002). In this study this could be due to large abundance of $D$. spectabile in all plots, which has increased markedly since possum control started at Otari's in the 1990's (de Almeida et al. 2009). Furthermore, the large number of rare species (those found in $7 \%$ or less of total number of plots) could be somehow influencing the results, as only presence of absence of a species is important and not its abundance in the co-occurrence analysis.

Seedlings results matched random expectations in all aspects. This could be due to the fact that there are several avian pollinators and seed dispersers in OtariWilton's Bush (e.g. tui, Prosthemadera novaeseelandiae and kereru, Hemiphaga novaeseelandiae), therefore birds may be helping to reduce recruitment limitation in the reserve and as competition may not yet be strong enough, randomness prevails among seedlings co-occurrence.

The overall pattern observed was that species richness was higher at lower abundance, and lower with higher abundance for both adult plants and seedlings. This is consistent with the competition theory which suggests that competition, (in this case increasing abundance of individuals) can increase extinction rates, seen as the decline in species richness (Mac Arthur \& Wilson 1967; Bengtsson 1989).

Abundance of plant species displayed a positively relationship with the null model, for adults and seedlings, therefore, it may be that random dispersal events 
and/or stochastic population dynamics are main factors in determining patterns in abundance (Hubbell 2001). Alternatively, as mentioned before, the large number of pollen and seed dispersers birds at Otari's could be contributing significantly to the overall large number of plants in the reserve. Patterns of the abundance of most plant species displayed a negative relationship with the abundance of all other species for both adults and seedlings. This is perhaps an indicative competition, which is expected to increase with abundance of other individuals (Diamond 1975). Competition can result in character displacement; however it can be minimized by promoting phenotypes associated with resource use (Pfennig \& Pfennig 2005). For this reason when many individuals are present in a given locale, species diversity decreases but not necessarily abundance.

Niche overlap results for adult plants showed that overlap is higher than expected under the null model. This could be due to the fact that species overlap increase as space decreases, given that space is a limiting factor. Differently, for seedlings, niche overlap matched the null model, therefore, overlap is minimal, and this could be due to the different strategies used by seedlings by growing faster in order to outcompete other species in the race for sunlight. Therefore, to begin with, all species have the same chance of becoming established in the community, however, when as seedlings grow competition for space becomes fiercer, due to increase in plant size vertically (height) and horizontally (diameter), thus an increase in niche overlap is expected.

Overall, determinist appears to shape community composition of adult plants at Otari Wilton's Bush, however, some aspects of the community were stochastic. Seedling community, on the other hand, appears to be shaped by randomness and stochasticity, however, some aspects in the community display to some degree 
determinist evidence. Going back to the old argument between Gleason and Clements, which theory appears to be correct? Both, as communities do not tend to be exclusively assembled by determinism or stochasticity. The use of null models seems as a good start point to study community assembly. Therefore, although some communities may display either a more determinist or stochastic aspect in it, a mixture of both appears to be the rule. Thus, more emphasis should be given in synthesising neutral (stochastic) and niche models in order to provide better explanations for community structure (Leibold \& McPeek 2006). 


\section{References}

Aguiar M.R., Lauenroth W.K. \& Peters D.P. (2001). Intensity of intra- and interspecific competition in coexisting shortgrass species. Journal of Ecology, 89, 40-47.

Alonso D., Etienne R.S. \& McKane A.J. (2006). The merits of neutral theory. TRENDS in Ecology and Evolution, 21, 451-457.

Anderson K.J. (2007). Temporal patterns in rates of community change during succession. The American Naturalist, 169, 780-793.

Bengtsson J. (1989). Irterspecific competition increases local extinction rate in a Metapopulation system. Nature (London), 340, 713-715.

Blick R., Bartholomew R., Burrell T. \& Burns K.C. (2008). Successional dynamics after pest eradication in the Karori Wildlife Sanctuary. New Zealand Natural Science, 33, 3-14.

Burns K. C. \& Dawson J. (2005) Patterns in the diversity and distribution of epiphytes and vines in a New Zealand forest. Austral Ecology, 30, 891-9.

Burns K.C. (2007). Is tree diversity different in the Southern Hemisphere? Journal of Vegetation Science, 18, 307-312.

Cavieres, L., Arroyo, M.T.K., Penaloza, A., Molina-Montenegro, M. \& Torres, C. (2002). Nurse effect of Bolax gummifera cushion plants in the alpine vegetation of the Chilean Patagonia Andes. Journal of Vegetation Science, 13, $547-554$.

Cavieres, L.A. \& Badano, E.I. (2009). Do facilitative interactions increase species richness at the entire community level?. Journal of Ecology, 97, 1181-1191.

Chase J.M. (2003). Community assembly: when should history matter? Oecologia, $136,489-498$. 
Chave J., Muller-Landau H.C. \& Levin S.A. (2002). Comparing Classical Community Models: Theoretical Consequences for Patterns of Diversity. The American Naturalist, 159, 1-23.

Clements F.E. (1916). Plant Succession: An Analysis of the Development of Vegetation. Washington D.C. Carnegie Institute of Washington.

Collins S. L. \& Glenn S. M. (1991) Importance of spatial and temporal dynamics in species regional abundance and distribution. Ecology, 72, 654-64.

Connell J.H. \& Slatyer R.O. (1977). Mechanisms of succession in natural communities and their role in community stability and organization. The American Naturalist, 111, 1119-1144.

Connor E.F. \& Simberloff D. (1979). The assembly of species communities: chance or competition? Ecology, 60, 1132-1140.

Council W.C. (2007). Otari Native Botanic Garden and Wilton's Bush reserve

Craine J.M. (2005). Reconciling plant strategy theories of Grime and Tilman. Journal of Ecology, 93, 1041-1052.

Davis M.A., Pergl J., Truscott A.M., Kollmann J., Bakker J.P., Domenech R., Prach K., Prieur-Richard A.H., Veeneklaas R.M., Pysek P., del Moral R., Hobbs R.J., Collins S.L., Pickett S.T.A. \& Reich P.B. (2005). Vegetation change: a reunifying concept in plant ecoloy. Perspectives in Plant Ecology, Evolution and Systematics, 7, 69-76.

Dawson J. \& Lucas R. (2000). Nature Guide to New Zealand Forest. Random House New Zealand, Auckland, New Zealand.

de Almeida D.C., Siva A. \& Burns K.C. (2009). Changes in tree abundance over 15 years at Otari: Succession or possum control? New Zealand Natural Sciences, 34, 9-18. 
Diamond, J.M. (1975). Assembly of species communities. - In: Cody, M.L. and Diamond, J.M. (eds), Ecology and evolution of communities. Harvard Univ. Press, Cambridge, MA, pp. 342-444.

Egler F.E. (1954). Vegetation science concepts I. Initial floristic composition, a factor in old-field vegetation development. Plant Ecology, 4, 412-417.

Feinsinger P., Spears E.E. \& Poole R.W. (1981). A simple measure of niche breadth. Ecology, 62, 27-32.

Finegan B. (1984). Forest succession. Nature, 312, 109-114.

Gleason H.A. (1926). The individualistic concept of the plant association. Bulletin of the Torrey Botanical Club, 53, 7-26.

Gotelly, N.J., Buckley, N.J. \& Wiens, J.A. (1997). Co-ocurrence of Australian land birds: Diamond's assembly rules revisited. Oikos, 80, 311-324.

Gotelli N.J. \& Colwell R.K. (2001). Quantifying biodiversity: procedures and pitfalls in the measurement and comparison of species richness. Ecol. Lett., 4, 379391.

Gotelli N.J. \& Entsminger G.L. (2007). EcoSim: Null models software for ecology. Version 72007 [http://garyentsminger.com/ecosim/index/htm]. Acquired intelligence Inc. \& Kesey-Bear. Jericho, VT 05465,USA.

Gotelli N.J. \& Grave G.R. (1996). Null models in ecology. Smithsonian Press, Washington DC.

Grime J.P. (1974). Vegetation classification by reference to strategies. Nature, 250, 26-31.

Hubbell S.P. (2001). The unified neutral theory of Biodiversity and Biogeography. Princeton University Press. 
Hubbell S.P. (2005). Neutral theory in community ecology and the hypothesis of functional equivalence. Functional Ecology, 19, 166-172.

Huckle J.M., Marrs R.H. \& Potter J.A. (2002). Interspecific and intraspecific interactions between salt marsh plants: Integrating the effects of environmental factors and density on plant performance. Oikos, 96, 307-319.

Laughlin D.C. \& Abella S.R. (2007). Abiotic and biotic factors explain independent gradients of plant community composition in ponderosa pine forests. Ecological Modelling, 205, 231-240.

Leibold M.A. \& McPeek M.A. (2006). Coexistence of the Niche and Neutral Perspectives in Community Ecology. Ecology, 87, 1399-1410.

Lester P.J., Abbott K.L., Sarty M. \& Burns K.C. (2009). Competitive assembly of South Pacific invasive ant communities. BMC Ecology, 9, Article No.: 3.

Lieberman M. \& Lieberman D. (2007). Nearest-neighbor tree species combinations in tropical forest: the role of chance, and some consequences of high diversity. Oikos, 116, $377-386$.

Lortie C.J., Brooker R.W., Choler P., Kikvidze Z., Michalet R., Pugnaire F.I. \& Callaway R.M. (2004). Rethinking plant community theory. Oikos, 107, 433438.

Mac Arthur R.H. \& Wilson E.O. (1967). The theory of island biogeography. Monographs in Population Biology. In: The theory of island biogeography. Monographs in Population Biology. Princeton University Press, p. xi+203p. Illus.

Marjot Y.T. (1992). Sixty years of change in a forest reserve: Otari Plant Museum, Wilton, Wellington. . In. Victoria University of Wellington. MSc. 
Perry, G.L.W., Enright, N.J., Miller, B.P., Lamont, B.B. \& Etienne R.S. (2009). Dispersal, edaphic fidelity and speciation in species-rich Western Australian shrublands: evaluating a neutral model of biodiversity. Oikos, 118, 1349 1362.

Pfennig, K.S \& Pfennig, K.W. (2005). Character displacement as the "best of a bad situation": Fitness trade-offs resulting from selection to minimize resource and mate competition. Evolution, 59, 2200-2208.

Rarefact 1.0 [http://people.hofstra.edu/j_b_bennington/research/paleoecology/ rarefact.html]

Ribichich A. M. (2005) From null community to non-randomly structured actual plant assemblages: parsimony analysis of species co-occurrences. Ecography, 28, $88-98$.

Ricklefs R.E. (2006). The unified neutral theory of biodiversity: Do the numbers add up? Ecology, 87, 1424-1431.

SPSS: SPSS for Windows, version 16.0.1. Chicago: Lead technologies; 2007.

Stone, L. \& Roberts, A. (1990). The checkerboard score and species distributions. Oecologia, 85, 74-79.

Tilman D. (1985). The resource-ratio hypothesis of plant succession. American Naturalist, 125, 827-852.

Walker L.R. \& del Moral R. (2003). Primary Succession and Ecosystem Rehabilitation. Press Syndicate of the University of Cambridge.

Wilson J.T. \& Chiarussi A. (2000). Do plant communities exist? Evidence from scaling up local species-area relations to the regional level. Journal of Vegetation Science, 11, 773-775. 
Zobel M. (1992). Plant species coexistence: The role of historical, evolutionary and ecological factors. Oikos, 65, 314-320. 


\section{Chapter 2: Relationship between a plant trait and environmental conditions in a New Zealand forest.}

\section{Abstract}

Leaf mass per area (LMA) is one of the most widely researched plant traits. Because LMA indexes a large amount of information of ecological importance it is of high interest for plant ecologists and ecophysiologists. Evidence suggests a positive correlation between environmental conditions and LMA. Vertical and horizontal variation in environmental conditions is often the subject of study on a large scale such as latitude and longitude. However, variation on a smaller scale such as within a tree (vertically) or within a forest (horizontally) are often overlooked. The aim of the present study was to investigate whether there is a relationship between a plant trait (LMA) and environmental conditions in a New Zealand forest. Thirty $30 \mathrm{~m} \times 30 \mathrm{~m}$ plots were surveyed. Species found in five or more of the plots had the height of two individuals taken, and from each individual six fully exposed leaves were collected and analysed. Measurements of environmental conditions were also collected for all plots. Principal component analysis and multiple regression was used to analyse the data. Height related (vertical) trends were observed for three surveyed species such that LMA significantly increased with plant height. Horizontal patterns were observed for two species, and for three species it was not possible to distinguish between the effects of tree height (vertical) and position along the forest (horizontal) on LMA. Potentially, by including more species in future studies a clearer pattern will be observed. It could also be that different species display different stratgies infleuncing their LMA and if so, a study more focused on individual species in isolation may be able to provide more informative explanations. 


\section{Introduction}

Leaf mass per area (LMA) is one of the most widely researched plant traits. LMA refers to leaf dried weight divided by its fresh area and because it indexes so much information of ecological importance it is of high interest for plant ecologists and ecophysiologists (Lusk et al. 2008). LMA which is the opposite of SLA (Specific leaf area) is seen as a key trait in plant growth (Lambers \& Poorter 1992; Hikosaka et al. 2005) and an important indicator of plant strategies (Wright \& Westoby 2002; Westoby 2007; Poorter et al. 2009). LMA is trait also widely used in plant ecology, agronomy and forestry (Poorter et al. 2009). Globally, across species LMA is positively correlated with leaf life span (Williams et al. 1989; Wright \& Cannon 2001; Campanella \& Bertiller 2009) and negatively correlated with transpiration and respiration rate (Givnish 1988) which in turn is associated with lower photosynthetic capacity (Lusk et al. 2008).

High LMA leaves have more mesophylls per unit area (Pandey \& Kushwaha 2005). Therefore, high LMA leaves are expected to photosynthesise better in the abundance of sunlight, whereas low LMA leaves are expected to do better where sunlight is scarcer. Although sunlight is an important environmental condition which affects plant traits (in this case LMA), conditions such as soil fertility and dryness can also influence LMA. For example, species growing on dry and infertile soil converged towards higher LMA, and those high LMA leaves also had a higher life span than species growing on more productive environments (Wright et al. 2002).

Environmental conditions have a strong influence on many plant functional traits such as wood density (Thomas et al. 2007) and leaf size (Poorter \& Rozendaal 2008). This environmental influence can be on a large scale (globally) or smaller scale (locally). In addition, environmental variation can occur within a forest both, 
vertically (from forest floor to canopy) and horizontally (at different locales in the forest).

Variation in environmental conditions is observed across a whole range of spatial gradients. Globally a strong variation in environmental conditions is observed across a latitudinal (horizontal variation) gradient; as we move away from the equator, sunlight and subsequently temperature tends to decrease and alongside this change in environmental conditions, plant traits also tend to change to match the environment. Species growing closer to the equator $\left(15^{\circ}\right)$ have a greater mean maximum height 29 times greater than those growing between $60-75^{\circ}$ and 31 times greater than those growing $45-60^{\circ}$ (Moles et al. 2009). It has been also suggested that along a latitudinal gradient, plants also display different strategies in nutrient conservation (Yuan \& Chen 2009).

Altitude (vertical variation) has also a strong effect on plant traits. Craine \& Lee (2003) while studying grass species along an altitudinal gradient in New Zealand found that plants in higher altitudes generally have thicker leaves and roots compared to those at lower altitudes. There is also a negative correlation between altitude and plant height (Totland \& Birks 1996). These changes in plant traits along an altitudinal gradient are an adaptation to the environmental conditions which change with altitude, the most conspicuous being perhaps the negative correlation between altitude and temperature (Totland 2001).

To a smaller extent, such as within a forest or reserve environmental conditions also vary. Environmental conditions differ between forest floor and canopy (vertical variation) and at different locations within the same forest (horizontal variation) (Chazdon \& Fletcher 1984; Oshima et al. 1997). Research shows that many plant traits tend to co-vary with environmental conditions (Ellsworth \& Reich 1993; 
Anten \& Werger 1996). Perhaps, one of the best know examples is that SLA tend to be lower (thicker or denser leaf tissue) in plants growing in high-insolation environments (Cunningham et al. 1999; Fonseca et al. 2000; Burns 2004). Perhaps, the niche theory may be one way to explain this co-variation.

The ecological niche theory (Hutchinson 1959; Yanez-Espinosa et al. 2003) describes how an organism or population responds to the distribution of resources and competitors (e.g., by growing when resources are abundant, and when predators, parasites and pathogens are scarce) and how it in turn alters those same factors (e.g., limiting access to resources by other organisms, acting as a food source for predators and a consumer of prey). For example, individual plant species have a set of physiological traits which allow them to survive and thrive in a given environment. It could be that, in the case of LMA, only species with high LMA are able to thrive in a certain type of environment, in the same manner Darwin finches can coexist by feeding on the same food source, by exploiting different fruit size.

Niche is divided into two different categories, the fundamental and the realized niche. The fundamental niche of a species includes the total range of environmental conditions that are suitable for existence without the influence of interspecific competition or predation from other species; it is the minimum requirement of a species for survival. For example, Scherzinger (2009) found that distribution of Capercaillie stretches from eastern Siberia to Western Europe. Within this area habitats are characterized by coniferous trees, dwarf shrubs like heather and bilberries, diverse flowers, leaves, and herbs for nutrition, whereby the birds choose the best combination of these resources in each location. Therefore, the best combination of these resources is Capercaillie fundamental niche. The realized niche describes that part of the fundamental niche actually occupied by the species. In the 
same study it was found that within this area Capercaillie have certain preferences in the quality of their habitat, and tend to occupy certain areas over others (realized niche) (Scherzinger 2009). The main difference between the fundamental and realized niche is the effect that competition and predation has on species. Within a forest, differences in environmental conditions may create certain conditions which only favour some traits to succeed by creating "niches". This set of environmental conditions play an important role in allowing certain traits to thrive over others depending on the combination of environmental conditions; it can be alleged that the environment is acting like a filter.

Much study in community ecology focuses in how environmental conditions can affect individuals within a community (Yanez-Espinosa et al. 2003; Valladares et al. 2000; Osada et al. 2001). The relationship between environment and plant form has played a central role in plant ecology and convergent evolution (Ackerly et al. 2002). There are two main ways in which organisms can be influenced by the environment. The first term to be described is know as co-gradient variation (which leads to convergence of traits) which is the similarity of plastic and evolutionary responses to an environmental gradient; such that environmental effects on phenotypic expression reinforce genetically determined differences between populations or species (Lusk et al. 2008). For example, it has been found that leaf lifespan is often longer in shaded individuals than in those growing in brighter light (Ackerly \& Bazzaz 1995; Reich et al. 2004). Leaves have a genetic predisposition to last longer in shade, as it is more costly for the plant to create a new leave rather than maintaining an existing one and this genetic predisposition is reinforced in the shade. Photosynthetic capacity and respiration rates are also usually lower in plants growing in the shade compared to those growing in higher light (Walters \& Reich 1999) as 
plant metabolism is lowered down in the absence of sun, again, a genetic imprint that is reinforced by the environment. Another pattern found in relation to plant traits and environment is termed counter-gradient variation, where environmental effects on phenotypic expression masks genetically determined differences between populations or species (Lusk et al. 2008).

The aim of this research is to test if there are relationships among species between a plant trait (LMA) and environmental conditions (vertically and horizontally) in a New Zealand forest.

\section{Methods}

\section{Study site}

Otari-Wilton's Bush $\left(41^{\circ} 14^{\prime} \mathrm{S}, 174^{\circ} 45^{\prime} \mathrm{E}\right)$ is located just within Wellington city limits at the southern tip of the North Island of New Zealand, and encompasses approximately 100 hectares of native forest. The reserve is situated 70-280 meters above sea level and the soil is comprised of stoney colluvium of greywacke parent material. Average annual rainfall totals 1,240 millimetres and average daily temperatures range from $20^{\circ} \mathrm{C}$ in summer to $7^{\circ} \mathrm{C}$ in winter (Council 2007). The vegetation is classified as coastal conifer-broadleaved forest, whose vertical structure is highly complex and similar to most tropical forests (Dawson \& Lucas 2000) .It has a fairly continuous canopy, which is frequently interrupted by canopy gaps and canopy emergent tree species. A dense community of shrubs and tree ferns occurs beneath the canopy (Blick et al. 2008) .Lianas and epiphytes are also abundant (Burns \& Dawson 2005). Dysoxylum spectabile is the dominant canopy-forming species, alongside Melicytus ramiflorus, Corynocarpus laevigatus and Elaeocarpus dentatus. Macropiper excelsum and Geniostoma rupestre are the most common subcanopy 
shrubs. Emergent trees include Dacrydium cupressinum, Beilschmedia tawa and Knightia excelsa. Burns (2007) gives a detailed inventory of the woody plant community.

\section{Data collection I - Plots}

Thirty $30 \mathrm{~m} \times 30 \mathrm{~m}$ plots encompassing a range of environmental conditions were surveyed within the reserve (following Marjot 1992). As it was desired to cover a range on environmental conditions, locations for placement of plots were chosen prior using a map of the reserve. Once in the chosen location a random number was generated using a calculator, if even, plot would be placed on the right side of the track, if odd, plot would be placed on the left side of the track. Again, another random number was generated in order to decide how many steps would be walked in the chosen direction, were the centre of the plot would be placed. A compass was also used to assure that a straight line from the track to the desired location of the plot in order to avoid sampling bias. However, some restrictions were applied regarding the location of the plots.

In each plot abundance of sexually mature vascular woody species was recorded. Sexually mature individuals are defined in this study as those capable of reproducing. Clues such as presence of fruit and/or flowers or evidence of such were used in deciding whether or not to include an individual in the study.

\section{Data collection II - Individual species}

Once the abundance of mature individuals was recorded, the second step was to collected information on individual plants. Species present in five or more of the plots were re sampled, only those found in at least five of the plots were used in order 
to provide more robust comparisons. Emergent species (Beilschmedia tawa and Knightia excelsa) and Podocarps were also not resurveyed due to restriction in collection of leaves from these individuals.

In each plot, the tallest two individuals of each species had their height measured. Height was measured with the use of a hypsometer (Nikon Forestry 550), and was taken from the base to the uppermost branch of the plant. Once height was measured, each individual had six leaves collected, except Dysoxilum spectabile which has large compound leaves, and had leaflets collected. Leaflets are likely to be functionally equivalent to leaves (Bongers \& Popma 1990; Niinemets et al. 2007). Only leaves fully exposed to sunlight from the outer part of the branch were collected for trees, for shrubs, leaves on the top of the plant were collected. Once collected leaves were placed into a paper bag, and taken to the lab for further measurements.

\section{Data collection III - physical aspects of plots}

Data regarding physical aspect of each plot was also collected. Information on plot aspect was collected using a compass; slope was collected using a hypsometer (Nikon Forestry 550). A soil tester with $30 \mathrm{~cm}$ probes was used to measure ph and soil moisture in the upper layer $(\leq 30 \mathrm{~cm})$ of the forest floor, measurement on soil moisture was given on a scale between 1 and 10, with 1 being the driest and 10 the wettest. Ph was given on a scale between 3.5 (acidic) to 8 (alkaline).

Sunlight exposure was measured using a light meter and given in lux. Measurement was given on a scale between 0 (dark) to 2000 (light). Data on sunlight was collected on a day of clear sky with each plot was surveyed twice on the same day (one measurement in the morning and another in the afternoon). Sunlight was collected at a height of $1.5 \mathrm{~m}$ above the floor. 
Each measurement (sunlight, moisture and ph) was taken at five different areas of the plot (four corners and centre) and average value was then used in each plot for statistical analysis. Slope was taken from one end to another end of the plot in the direction the plot was facing; therefore, slope was measured for an area of $30 \mathrm{~m}$.

\section{Data collection IV - Lab}

The fresh leaves collected from individual plants had their area in $\mathrm{cm}^{2}$ measured using an area meter scanner. Fresh leaf area was recorded to an accuracy of three decimal points, and once measurements on area were made, leaves were dried for 48 hours at a temperature of $65^{\circ}$ (following Shuttleworth 1989; Wright et al. 2002) and dried weight was taken using an electronic scale. Weight was measured in mg to an accuracy of three decimal points. With those measurements, leaf mass per area (LMA) in $\mathrm{g} / \mathrm{m}^{2}$ was calculated and an average was given for each individual plant, based on the six collected leaves.

\section{Overall}

35 different species belonging to 33 different genera were found. Out of 35 species 13 were found in five or more of the plots. B. tawa and K. excelsa are emergent species; therefore leaves were not collected due to restrictions. Podocarps were also not sampled. Thus, eight species were used for further data collection and analysis. For each of the eight species, in each plot two plants had their height measured and in each plant six leaves were collected for further analyses. Total number of plant with height measured was 288 . In each of the 288 plants, six leaves were collected resulting in a total of 1,728 leaves. 


\section{Data analyses}

Principal component analysis (PCA), which is a type of factorial analyses, was used in order to reduce different components (in this case environmental conditions) into on axis (from hereafter referred to as PC1). PCA seeks a linear combination of variables such that the maximum variance is extracted from the variables. It then removes this variance and seeks a second linear combination which explains the maximum proportion of the remaining variance, and so on.

The main applications of factor analytic techniques are: (1) to reduce the number of variables and (2) to detect structure in the relationships between variables, that is to classify variables (Statsoft Inc. 2010). Therefore, factor analysis was applied as a data reduction or structure detection method.

By using PCA it was possible to reduce four measured environmental variables (sunlight, slope, aspect and $\mathrm{pH}$ ) into one axis (PC1). PC1 was then plotted against averaged LMA for each species for all the plots.

Multiple regression analysis was also used by applying the following formula in the data:

$\mathbf{Y}=\mathbf{a}+\mathbf{b}_{1} \mathbf{X}_{1}+\mathbf{b}_{2} \mathbf{X}_{2}+\ldots+\mathbf{b}_{\mathbf{p}} \mathbf{X}_{\mathbf{p}}$

Where:

$\mathbf{Y}$ is the value of the Dependent variable $(\mathrm{Y})$; what is being predicted or explained a (Alpha) is the Constant or intercept $b_{1}$ is the Slope (Beta coefficient) for $X_{1} \ldots$

Multiple regression can establish that a set of independent variables (height, PC1) explains a proportion of the variance in a dependent variable (LMA) at a significant level (through a significance test of $\mathrm{R}^{2}$ ), and can establish the relative 
predictive importance of the independent variables (by comparing beta weights)

(Statsoft Inc. 2010). Therefore, it is able to explain if whether PC1 or height have a stronger (significant) effect on LMA.

\section{Results}

The first principal component (PC1) explains $50.8 \%$ of the variance on moisture, $\mathrm{pH}$, sunlight and slope. PC1 was positively correlated with slope (.608) and sunlight (.807) and negatively correlated with moisture (-.970) and ph (-.314) Therefore higher PC1 values describe plots which are steeper, lighter, drier and slightly more acidic than plots with low PC1 value. PC1 values decreases when moving from north to south (see figure 1).

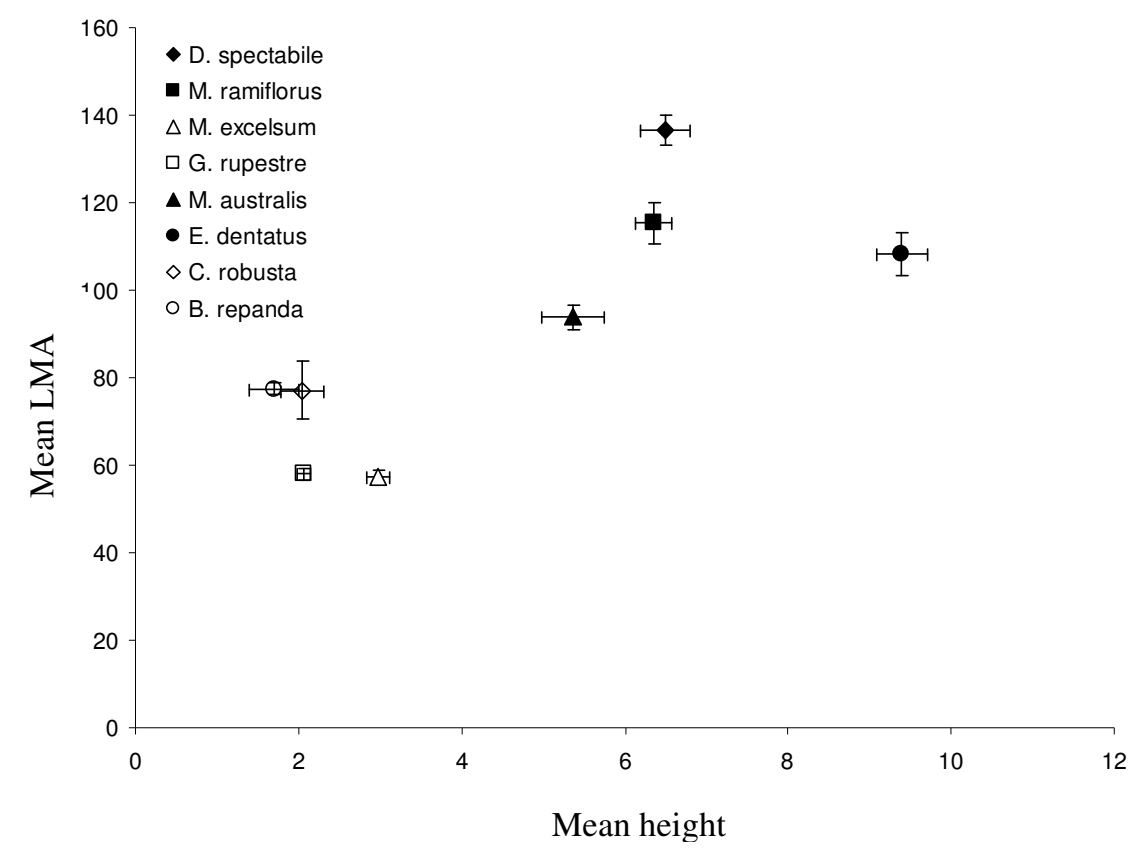

Figure 1. Average LMA against average height. A clear correlation between height and LMA is observed as higher plants also tend to have higher LMA. Open symbols are shrub species and closed symbols are tree species. 


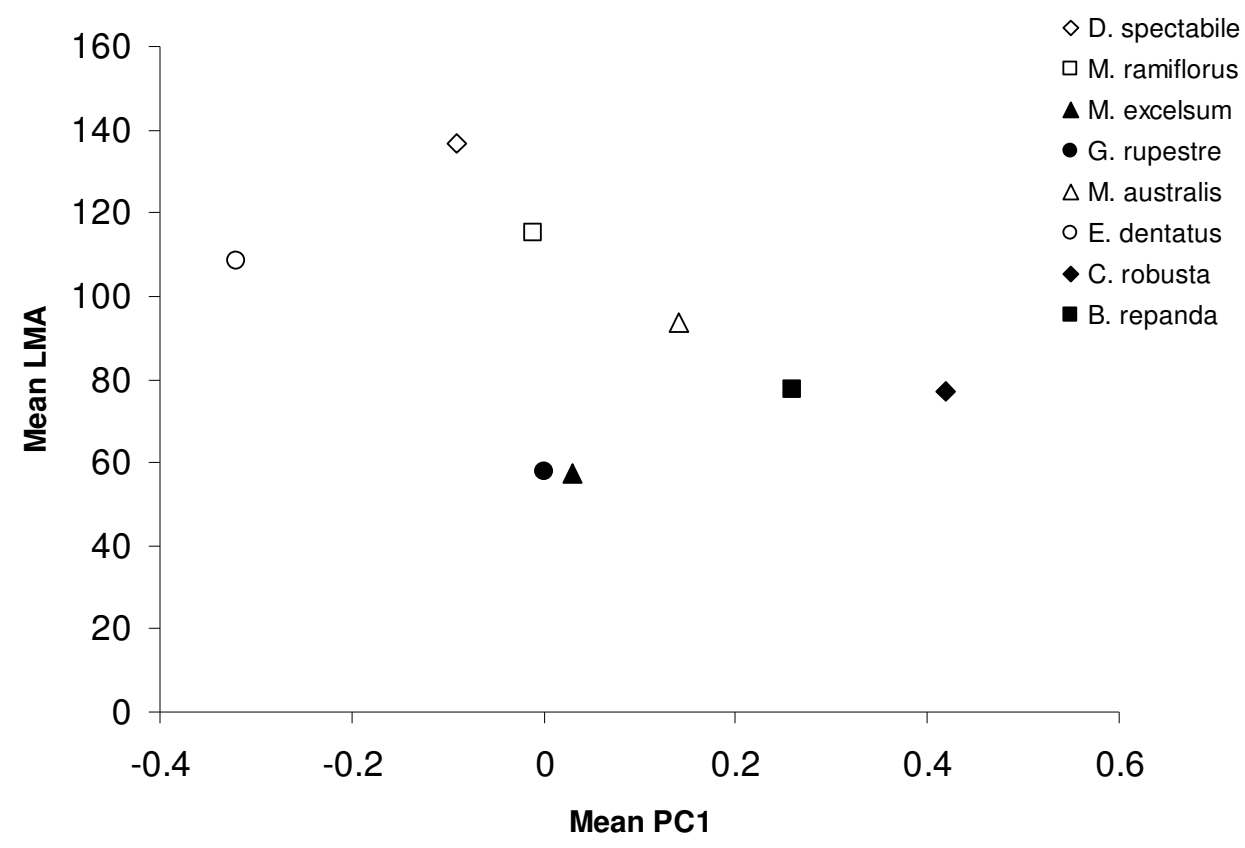

Figure 2. Mean LMA (g/m2) against mean PC1. Note that LMA displays a positive correlation with PC1 for shrubs (closed symbols), whereas for trees (open symbols) LMA displays a negative correlation with PC1.

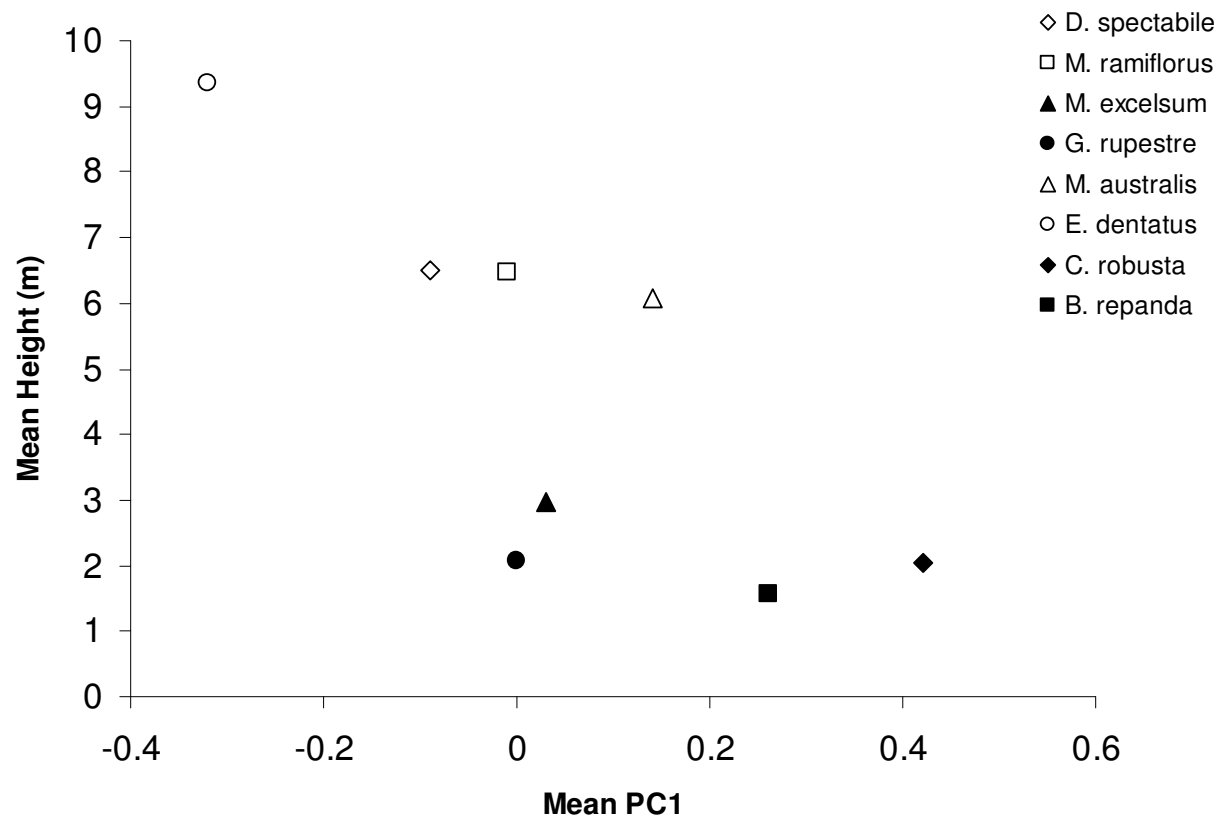

Figure 3. Mean height against mean PC1. Height tends to decrease with PC1 for both, trees (open symbols) and shrubs (closed symbols).

Horizontal patterns in plant diversity were observed. There is a positive correlation between average plant height and average LMA (figure 1). However, a different pattern was observed between average PC1 and average LMA (figure 2). For 
trees, a negative correlation was observed with PC1, as moving from South to North,

LMA tends to decrease (figure 1); for shrubs, the opposite pattern was observed as

LMA slightly increases with PC1. Height displayed a similar pattern for both trees as shrubs, as it tended to decrease with PC1 (figure 3).

Table 1. Multiple regression for Average LMA of each species. LMA was used as a dependent factor and PC1 and height as independent factors and separate analyses were conducted for each species. B corresponds to increase in LMA for each unit of either PC1 or height. $*=<0.05$ and $* *=<0.001$

\begin{tabular}{|c|c|c|c|c|}
\hline Species & $\begin{array}{l}\text { Predictor } \\
\text { variable }\end{array}$ & B & $\begin{array}{c}\text { Std. } \\
\text { Error }\end{array}$ & Beta \\
\hline \multirow[t]{3}{*}{ D. spectabile } & (Constant) & 125.075 & 16.095 & \\
\hline & PC1 & 6.441 & 2.824 & $0.491 *$ \\
\hline & Height & 1.887 & 2.435 & 0.167 \\
\hline \multirow[t]{3}{*}{ M. ramiflorus } & (Constant) & 14.111 & 21.767 & \\
\hline & $\mathrm{PC} 1$ & 0.058 & 3.707 & 0.002 \\
\hline & Height & 15.923 & 3.377 & $0.708 * *$ \\
\hline \multirow[t]{3}{*}{ M. excelsum } & (Constant) & 54.659 & 6.673 & \\
\hline & PC1 & 0.966 & 1.579 & 0.124 \\
\hline & Height & 0.929 & 2.180 & 0.086 \\
\hline \multirow[t]{3}{*}{ G. rupestre } & (Constant) & 57.618 & 5.589 & \\
\hline & $\mathrm{PC} 1$ & 3.001 & 1.240 & $0.422 *$ \\
\hline & Height & 0.193 & 2.636 & 0.013 \\
\hline \multirow[t]{3}{*}{ M. australis } & (Constant) & 63.479 & 19.217 & \\
\hline & $\mathrm{PC} 1$ & 7.661 & 4.603 & 0.801 \\
\hline & Height & 5.513 & 3.492 & 0.759 \\
\hline \multirow[t]{3}{*}{ C. robusta } & (Constant) & 33.788 & 15.585 & \\
\hline & PC1 & 6.380 & 3.896 & 0.461 \\
\hline & Height & 19.873 & 7.107 & $0.787 *$ \\
\hline \multirow[t]{3}{*}{ E. dentatus } & (Constant) & 17.773 & 39.350 & \\
\hline & PC1 & 5.283 & 5.231 & 0.275 \\
\hline & Height & 9.826 & 4.190 & $0.638 *$ \\
\hline \multirow[t]{3}{*}{ B. repanda } & (Constant) & 56.051 & 33.627 & \\
\hline & $\mathrm{PC} 1$ & 10.565 & 9.783 & 0.651 \\
\hline & Height & 10.984 & 21.086 & 0.314 \\
\hline
\end{tabular}


In order to analyze the effects height and PC1 have on LMA, a multivariate regression analyses was run on the data (see table 1). PC1 had a stronger effect on LMA than height for both D. spectabile and G. rupestre (Beta $=.491, \mathrm{p}<0.05$ and Beta $=.422$ and $\mathrm{p}<0.05$ respectively). For M. ramiflorus, $C$. robusta and E. dentatus, height appears to have a stronger effect on LMA than PC1 (Beta $=.708 \mathrm{p}<0.001$; Beta $=.787, \mathrm{p}<0.05$ and Beta $=638, \mathrm{p}<0.05$ respectively). No significant difference was observed between the effects of PC1 and height on LMA for M. excelsum, M. australis and $B$. repanda therefore it was not possible to differentiate between the effects of plant height and PC1 on leaf LMA for those species.

\section{Discussion}

Horizontal and vertical patterns in leaf LMA were observed. However, patterns differed between species vertically and horizontally. Height related (vertical) trends were observed for three surveyed species (M. ramiflorus, C. robusta and $E$. dentatus) as for those species LMA significantly increased with plant height. Horizontal patterns were observed for two species, (D. spectabile and G. rupestre), and for three species (M. excelsum, M. australis and B. repanda) it was not possible to distinguish between the effects of tree height (vertical) and position along the forest (horizontal).

\section{Vertical patterns}

Althought environmental conditions were not measured vertically in this study, evicence suggesting that environmental conditions such as light, temperature and humidity change vertically in forested environments (Oshima et al. 1997). Sunlight decreases deeper in the canopy and several microclimatic (vapour pressure 
deficeit, light quality) and physiological (leaf transpiration and carbon gain) parameters change with light intensity within plant canopies (Combes et al. 2000).

Overall the findings in this research suggests a relationship between LMA and plant height such that shrubs had lower LMA than trees. Previous research found similar patterns in leave traits, for example Beaumont \& Burns (2009) found that specific leaf area (the inverse of LMA) declined with plant height.. There are some advantages for plants to converge towards lower LMA in environments with less light, as it provides a better photosintetic capacity in such environments (Frak et al. 2002). Research shows that photon flux density incidence is two times higher in canopy leaves than understorey leaves (Pearcy 1983). This may be an indication of convergence of traits as different environmental conditions associated with plant height are causing leaves to converge towards morphological similarity. However, by investing more energy in LMA plants may affect other areas such as that interspecific variarion in LMA shows a strong negative correlation with seedlling growth rates (Lambers \& Poorter 1992), reflecting its value as an indicator of the cost of constructing leaf area (Villar \& Merino 2001). Thus, by increasing its LMA the plant is reducing its growth rate (in seedling at least). Intraspecifically, LMA of a given species tends to markedly increase as seedlings grow bigger (Lusk \& Warton 2007) when species are compared at a common size at a common environment. Again, this is evidence that vertically LMA tends to increase as amounto of sunlight tends to get higher when moving up from forest floor towards the canopy.

Also, shrub species had lower LMA compared to canopy species, and it is consistent with previous research, which suggests that LMA increases with height (Ellsworth \& Reich 1993). Research also showed that whithin species, a large variation in leaf traits is observed within the same plant at different heights (vertical 
gradient) (Beaumont \& Burns 2009). This could also be interpreted as evidence of niche partitioning, as higher plants, which also have leaves with higher LMA partition the top of the forest, whereas smaller plants, which have low LMA partition lower heights. Therefore, amount of sunlight is the fundamental niche for leaves with higher of lower LMA. This is consistent with previous research, which found that within a plant, traits differ for leaves taken from different heights at the same plant (Beaumont \& Burns 2009). However, it is not possible to know if trait or environment came first. If environment came first, traits can be seen as adaptation, if traits came first, natural selection comes into play and adaptation plays an important role in this "niche division" (see Ackerly 2004 for more on the subject). A phylogenetic study may also be able to answer this question by comparing plant phylogeny with LMA.

In the present study, plant height was similar for both, within trees and within shrubs (excep E. dentatus), therefore it may indicate that environment does not have a strong effect on plant height within the forest. However, there are patterns globally, as plants tend to get smaller when moving away from the Equator towards higher latitudes (see Moles et al. 2009), and also when moving from lower to higher altitudes plants tend to get smaller (Gao \& Zhang 2006).

\section{Horizontal patterns}

Differently from what was observed vertically, interspecifically correlation between horizontal variation in environmental conditions and LMA is not clearly noticed in the reserve (i.e. LMA does not significantly differs from areas of low sunlight and areas of high sunlight). However, when dividing species into trees or shrubs, some patterns were observed. In shrubs, LMA increased with PC1 (moving from $\mathrm{S}$ to $\mathrm{N}$ ), conversely, for trees, LMA tended to decrease as PC1 increased. Research shows that plants growing in dry, sunnier environments (characteristic of 
high PC1 values in this research) tend to have higher LMA than those growing in areas more humid and with less light (Wright et al. 2002) .Therefore, one would expect that all surveyed species would show an increase in LMA when moving from South to North. This is consistent with findings that Ackerly et al. (2002) observed while studying a chaparral in California where SLA was correlated with environment, such that species with low SLA were more abundant in areas with high light, whereas species with high SLA were more abundant in areas with low sunlight. In this study a similar pattern was observed for shrub species but not for trees. This could be due to the fact that trees have unrestricted access to sunlight, and perhaps, amount of sunlight between North and South facing does not differ to such a degree that it will affect plant strategy (i.e. increasing LMA on North facing slopes). Furthermore, Frak et al. (2002) found that not only light levels are important in photosynthetic acclimation of tress, but also light quality, perhaps, no difference in quality of light is observed in the canopy between north and south facing slopes. Two species $(D$. spectabile and $G$. rupestre) leaf LMA were strongly affected by variation in PC1 (horizontally). These species where also the two most abundant specie in the survey, and perhaps this could be due to the fact those plants can adapt to different environmental conditions better than other species, being able to explore and adapt to a wider range of environmental conditions.

Not only is LMA an adaptation to increase photossyntetic capacity. There are other advantages for the plant in matching LMA with environment. For example, in a cafeteria style study, it has been show that low LMA leaves are eaten preferably by herbivores (Cornelissen et al. 1999; Louault et al. 2005) and the same preference was also observed in the field (Perez-Harguindeguy et al. 2003). Furthermore, Bach (1984) while studying betlle herbivory found that number of bettles are significantly 
reduced under shaded conditions, therefore, herbivory would be higher under light conditions, thus, it may be advantageous to the plant to have higher LMA in areas with more sunlight. Damour et al. (2008) found that drought has a strong effect on LMA as plants growing under water strees have a higher LMA than those growing in the presence of water. This may be the case investing more in maintaining a leaf instead of making a new one.

\section{Conclusion}

Althought some patterns regarding environment and plant trais were observed, results are not very conclusive as different species appear to respond differently to the environment. Perhaps a study with more variables (both, environmental and plant traits) may provide more informative results. Potentially, by including more species in future studies a clearer pattern will be observed. It could also be that different species display different strategies influencing LMA and if so, a study more focused on individual species in isolation may be able to provide more informative explanations. 


\section{References}

Ackerly D.D. (2004). Adaptation, Niche Conservatism, and Convergence:

Comparative Studies of Leaf Evolution in the California Chaparral. The American Naturalist, 163, 654-671.

Ackerly D. D. \& Bazzaz F. A. (1995). Seedling crown orientation and interception of diffuse radiation in tropical forest gaps. Ecology, 76, 1134-46.

Ackerly D.D., Knight C.A., Weiss S.B., Barton K. \& Starmer K.P. (2002). Leaf size, specific leaf area and microhabitat distribution of chaparral woody plants: Contrasting patterns in species level and community level analyses. Oecologia (Berlin), 130, 449-457.

Anten N. P. R. \& Werger M. J. A. (1996). Canopy structure and nitrogen distribution in dominant and subordinate plants in a dense stand of Amaranthus dubius L. with a size hierarchy of individuals. Oecologia, 105, 30-7.

Bach C. E. (1984). Plant spatial pattern and herbivore population dynamics plant factors affecting the movement patterns of a tropical cucurbit specialist acalymma-innubum. Ecology, 65, 175-90.

Beaumont S. \& Burns K. C. (2009). Vertical gradients in leaf trait diversity in a New Zealand forest. Tree, 23, 339-46.

Blick R., Bartholomew R., Burrell T. \& Burns K.C. (2008). Successional dynamics after pest eradication in the Karori Wildlife Sanctuary. New Zealand Natural Science, 33, 3-14.

Bongers F. \& Popma J. (1990). Leaf characteristics of the tropical rain-forest flora of Los-Tuxtlas, Mexico. Botanical Gazette, 151, 354-365.

Burns K.C. (2004). Patterns in specific leaf area and the structure of a temperate heath community. Diversity Distribution, 10, 105-112. 
Burns K.C. (2007). Network properties of an epiphyte metacommunity. Journal of Ecology, 95, 1142-1151.

Burns K. C. \& Dawson J. (2005). Patterns in the diversity and distribution of epiphytes and vines in a New Zealand forest. Austral Ecology, 30, 891-9.

Campanella M.V. \& Bertiller M.B. (2009). Leafing patterns and leaf traits of four evergreen shrubs in the Patagonian Monte, Argentina. Acta Oecologica, 35, 831-837.

Chazdon R. L. \& Fletcher N. (1984). Photosynthetic light environments in a lowland tropical rain-forest in Costa Rica. Journal of Ecology, 72, 553-64.

Combes D., Sinoquet H. \& Varlet-Grancher C. (2000). Preliminary measurement and simulation of the spatial distribution of the morphogenetically active radiation (MAR) within an isolated tree canopy. Annals of Forest Science, 57, 497-511.

Cornelissen J.H.C., Perez-Harguindeguy N., Diaz S., Grime J.P., Marzano B., Cabido M., Vendramini F. \& Cerabolini B. (1999). Leaf structure and defence control litter decomposition rate across species and life forms in regional floras on two continents. New Phytologist, 143, 191-200.

Council W.C. (2007). Otari Native Botanic Garden and Wilton's Bush reserve

Craine J.M. \& Lee W.G. (2003). Covariation in leaf and root traits for native and nonnative grasses along an altitudinal gradient in New Zealand. Oecologia (Berlin), 134, 471-478.

Cunningham S.A., Summerhayes B. \& Westoby M. (1999). Evolutionary divergences in leaf structure and chemistry, comparing rainfall and soil nutrient gradients. Ecological Monographs, 69, 569-588.

Damour G., Vandame M. \& Urban L. (2008). Long-term drought modifies the fundamental relationships between light exposure, leaf nitrogen content and 
photosynthetic capacity in leaves of the lychee tree (Litchi chinensis). Journal of Plant Physioogy.. 165, 1370-8.

Dawson J. \& Lucas R. (2000). Nature Guide to New Zealand Forest. Random House New Zealand, Auckland, New Zealand.

Ellsworth D. S. \& Reich P. B. (1993). Canopy structure and vertical patterns of photosynthesis and related leaf traits in a deciduous forest. Oecologia, 96, $169-78$.

Fonseca C.R., Overton J.M., Collins B. \& Westoby M. (2000). Shifts in traitcombinations along rainfall and phosphorus gradients. Journal of Ecology, 88, 964-977.

Frak E., Le Roux X., Millard P., Adam B., Dreyer E., Escuit C., Sinoquet H., Vandame M. \& Varlet-Grancher C. (2002). Spatial distribution of leaf nitrogen and photosynthetic capacity within the foliage of individual trees: Disentangling the effects of local light quality, leaf irradiance, and transpiration. Journal of Experimental Botany, 53, 2207-16.

Gao J.-F. \& Zhang Y.-X. (2006). Distributional patterns of species diversity of main plant communities along altitudinal gradient in secondary forest region, Guandi Mountain, China. Journal of Forestry Research, 17, 111-115.

Givnish T.J. (1988). Adaptation to sun and shade - A whole plant perspective. Australian. Journal of Plant Physiology, 15, 63-92.

Hikosaka K., Onoda Y., Kinugasa T., Nagashima H., Anten N. P. R. \& Hirose T. (2005). Plant responses to elevated CO2 concentration at different scales: leaf, whole plant, canopy, and population. Ecological Research, 20, 243-53.

Hutchinson G. E. (1959). Homage to Santa Rosalia;or, why there are so many kinds of animals? The American Naturalist, 94, 421-5. 
Lambers H. \& Poorter H. (1992). Inherent variation in growth rate between higher plants: a search for physiological causes and ecological consequences. Advances in Ecological Research, 23, 187-261.

Louault F., Pillar V. D., Aufrere J., Garnier E. \& Soussana J. F. (2005). Plant traits and functional types in response to reduced disturbance in a semi-natural grassland. Journal of Vegetation Science, 16, 151-60.

Lusk C.H., Reich P.B., Montgomery R.A., Ackerly D.D. \& Cavender-Bares J. (2008). Why are evergreen leaves so contrary about shade? Trends in Ecology \& Evolution, 23, 299-303.

Lusk C.H. \& Warton D.I. (2007). Global meta-analysis shows that relationships of leaf mass per area with species shade tolerance depend on leaf habit and ontogeny. New Phytologist, 176, 764-774.

Marjot Y.T. (1992). Sixty years of change in a forest reserve: Otari Plant Museum, Wilton, Wellington. . In. Victoria University of Wellington. MSc.

Moles A. T., Warton D. I., Warman L., Swenson N. G., Laffan S. W., Zanne A. E., Pitman A., Hemmings F. A. \& Leishman M. R. (2009). Global patterns in plant height. Journal of Ecology, 97, 923-32.

Niinemets U., Portsmouth A., Tobias M. (2007). Leaf shape and venation pattern alter the support investments within leaf lamina in temperate species: a neglected source of leaf physiological differentiation? Functional Ecology, 21, 28-40.

Osada N., Takeda H., Furukawa A. \& Awang M. (2001). Leaf dynamics and maintenance of tree crowns in a Malaysian rain forest stand. Journal of Ecology, 89, 774-82.

Oshima K., Tang Y. \& Washitani I. (1997). Spatial and seasonal patterns of microsite light availability in a remnant fragment of deciduous riparian forest and their 
implication in the conservation of Arisaema heterophyllum, a threatened plant species. Journal of Plant Research, 110, 321-7.

Pandey S. \& Kushwaha R. (2005). Leaf anatomy and photosynthetic acclimation in Valeriana jatamansi L. grown under high and low irradiance. Photosynthetica, 43, 85-90.

Pearcy R. W. (1983). The light environment and growth of 3 carbon pathway and 4 carbon pathway tree species in the understory of Hawaiian USA forest. Oecologia, 58, 19-25.

Perez-Harguindeguy N., Diaz S., Vendramini F., Cornelissen J. H. C., Gurvich D. E. \& Cabido M. (2003). Leaf traits and herbivore selection in the field and in cafeteria experiments. Austral Ecology, 28, 642-50.

Poorter H., Niinemets U., Poorter L., Wright I. J. \& Villar R. (2009). Causes and consequences of variation in leaf mass per area (LMA): a meta-analysis. New Phytologist, 182, 565-88.

Poorter L. \& Rozendaal D.M.A. (2008). Leaf size and leaf display of thirty-eight tropical tree species. Oecologia, 158, 35-46.

Reich P. B., Uhl C., Walters M. B., Prugh L. \& Ellsworth D. S. (2004). Leaf demography and phenology in Amazonian rain forest: A census of 40000 leaves of 23 tree species. Ecological Monographs, 74, 3-23.

Scherzinger W. (2009). The fundamental niche of the Capercaillie Tetrao urogallus. Ornithologischer Anzeiger, 48, 19-32.

Shuttleworth W. J. (1989). Micrometeorology of temperate and tropical forest. Philosophical Transactions of the Royal Society of London B Biological Sciences, 324, 299-334. 
StatSoft, Inc. (2010). Electronic Statistics Textbook. Tulsa, OK: StatSoft. WEB: http://www.statsoft.com/textbook/.

Thomas D. S., Montagu K. D. \& Conroy J. P. (2007) Temperature effects on wood anatomy, wood density, photosynthesis and biomass partitioning of Eucalyptus grandis seedlings. Tree Physiology, 27, 251-60.

Totland O. (2001). Environment-dependent pollen limitation and selection on floral traits in an alpine species. Ecology, 82, 2233-44.

Totland O. \& Birks H.J.B. (1996). Factors influencing inter-population variation in Ranunculus acris seed production in an alpine area of southwestern Norway. Ecography, 19, 269-278.

Valladares F., Wright S. J., Lasso E., Kitajima K. \& Pearcy R. W. (2000). Plastic phenotypic response to light of 16 congeneric shrubs from a Panamanian rainforest. Ecology, 81, 1925-36.

Villar R. \& Merino J. (2001). Comparison of leaf construction costs in woody species with differing leaf life-spans in contrasting ecosystems. New Phytologist, 151, 213-26.

Walters M.B. \& Reich P.B. (1999). Low-light carbon balance and shade tolerance in the seedlings of woody plants: Do winter deciduous and broad-leaved evergreen species differ? New Phytologist, 143, 143-154.

Westoby M. (2007). Plant ecological strategies. South African Journal of Botany, 73, 275-6.

Williams K., Field C.B. \& Mooney H.A. (1989). Relationships among leaf construction cost, leaf longevity, and light environment in rain-forest plants of the genus Piper. American Naturalist., 133, 198-211. 
Wright I.J. \& Cannon K. (2001). Relationships between leaf lifespan and structural defences in a low-nutrient, sclerophyll flora. Functional Ecology., 15, 351359.

Wright I. J. \& Westoby M. (2002). Leaves at low versus high rainfall: Coordination of structure, lifespan and physiology. New Phytologist, 155, 403-16.

Wright I. J., Westoby M. \& Reich P. B. (2002). Convergence towards higher leaf mass per area in dry and nutrient-poor habitats has different consequences for leaf life span. Journal of Ecology, 90, 534-43.

Yanez-Espinosa L., Terrazas T., Lopez-Mata L. \& Valdez-Hernandez J.I. (2003). Leaf trait variation in three species through canopy strata in a semi-evergreen Neotropical forest. Canadian Journal of Botany, 81, 398-404.

Yuan Z. Y. \& Chen H. Y. H. (2009). Global-scale patterns of nutrient resorption associated with latitude, temperature and precipitation. Global Ecology and Biogeography, 18, 11-8. 